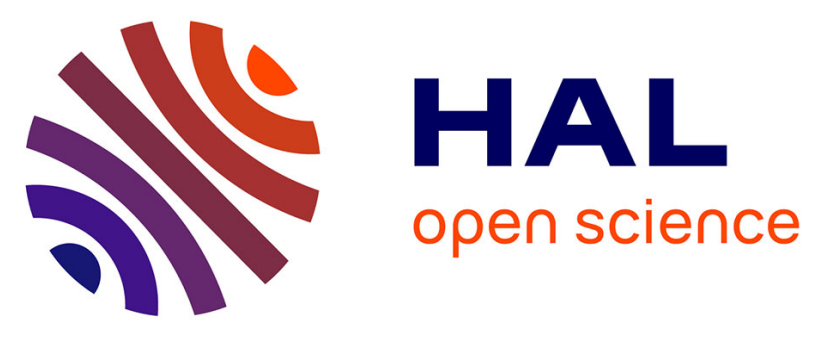

\title{
Characterization of moment resisting I-beam to circular hollow section column connections resorting to passing-through plates
}

Rajarshi Das, Alper Kanyilmaz, Maël Couchaux, Benno Hoffmeister, Herve Degee

\section{To cite this version:}

Rajarshi Das, Alper Kanyilmaz, Maël Couchaux, Benno Hoffmeister, Herve Degee. Characterization of moment resisting I-beam to circular hollow section column connections resorting to passingthrough plates. Engineering Structures, 2020, 210, pp.110356. 10.1016/j.engstruct.2020.110356 . hal-02798005

\section{HAL Id: hal-02798005 https://hal-univ-rennes1.archives-ouvertes.fr/hal-02798005}

Submitted on 23 Jun 2020

HAL is a multi-disciplinary open access archive for the deposit and dissemination of scientific research documents, whether they are published or not. The documents may come from teaching and research institutions in France or abroad, or from public or private research centers.
L'archive ouverte pluridisciplinaire HAL, est destinée au dépôt et à la diffusion de documents scientifiques de niveau recherche, publiés ou non, émanant des établissements d'enseignement et de recherche français ou étrangers, des laboratoires publics ou privés. 


\title{
Characterization of Moment Resisting I-beam to Circular Hollow Section Column Connections resorting to Passing-Through Plates
}

Rajarshi Das ${ }^{\mathrm{a}, 1}$, Alper Kanyilmaz ${ }^{\mathrm{b}}$, Mael Couchauxc, Benno Hoffmeisterd, Herve Degee ${ }^{\mathrm{a}}$

a Construction Engineering Research Group, Hasselt University, Hasselt, Belgium

${ }^{b}$ Department of Architecture, Built Environment and Construction Engineering, Politecnico di Milano, Italy

c Department of Civil and Urban Engineering, National Institute of Applied Sciences of Rennes, France

d Institute of Steel Construction, RWTH Aachen University, Germany

\begin{abstract}
Open-to-Circular Hollow Section (CHS) connections are highly encouraged nowadays in modern multistoried structures due to the extensive resistance provided by the CHS columns against high compression, tension as well as flexure in all directions, combined with their exceptional aesthetics. However, using more and more gusset plates or stiffeners to strengthen a conventional open-to-CHS connection causes economic disadvantage due to excessive welding quantities and substantial CHS chord yielding further limits any opportunity to exploit the full advantages offered by the open sections therefore minimizing its frequent application. However, if designed efficiently, the CHS connection can offer an extensive range of solutions which makes it an impeccable choice for the modern multi-storey structures. To that purpose, a "LASTEICON" solution is proposed in this paper investigating a "passing-through" concept, which is obtained by using laser cutting technology (LCT). Initially, a suitable moment resisting Plate-to-CHS-column connection is characterized through a detailed understanding of the relevant parameters, where the primary beams are connected at either side of the CHS column by two transverse and one longitudinal plate passing through the CHS column via laser cut slots. A detailed parametric study is conducted based on multiple Finite Element (FE) models primarily calibrated from an experimental campaign to understand the effect of each parameter and further verify and therefore establish the analytical assumptions to calculate the ultimate resistance of such connections. Finally a comprehensive design procedure is proposed to design such "passing-through" Plateto-CHS column connections. A short comparison study is also made with the conventional (direct weld) joints to highlight the advantages offered by this LASTEICON solution.
\end{abstract}

Keywords: Open-to-CHS-column connection; Tubular structures; CHS joints; Hollow section joints; Through Plate connections; Passing-through joints.

\section{INTRODUCTION}

Existing structural examples with Circular Hollow Sections (CHS) demonstrate their excellent properties in resisting high compression, tension as well as bending in all directions, thanks to their inherent shape and geometry [1] along with an aesthetic architectural appearance. Furthermore, compared to equivalent open sections, the CHS have proved to be a better shape for structural members under wind-, water- or waveloading scenarios [2] while absence of sharp corners make them more efficient towards corrosion protection [2]. Additionally, a lesser volume requirement of fire protection material [3] and an easy filling with concrete (composite behaviour), makes it an attractive solution towards fire resistance [4]. Almost 40\% lighter structures are obtained when compared to similar structures with open sections [5]. Although the unit material cost of hollow sections is somewhat higher than that of open sections, this is compensated by the reduced weight of construction, smaller painting area for corrosion protection, lesser requirement of fire protection material and reduction of fabrication cost, thanks to the aforementioned properties. Many examples of hollow section structures thus show that the CHS can economically compete with designs in open sections [2]. Therefore, over the past few decades, researches have tried to implement such hollow sections in

$\mathbf{1}$ corresponding author, e-mail address: rajarshi.das@uhasselt.be 
the structural connections to improve their global resistance by exploiting the significant advantages in offer. In today's industry, an open-to-hollow section connection is generally constructed by connecting the open sections to the CHS (or RHS) column surface by direct welding technique or implementing local stiffeners/gusset plates. In the last five decades of research on structural hollow sections, CIDECT has provided significant knowledge base and conceptual understanding in the field of stability, fire protection, wind loading, composite construction, and the static and fatigue behaviour of several different types of opento-hollow section joint connections. Several design guides and research papers have been documented by CIDECT for efficient yet safe application of structural hollow sections and their connections [6-12] based on successful identification of the force-transfer mechanics.

Significant drawbacks were however noticed in some research studies. For most of these connections, the failure was dominated by a localized yielding of the CHS column [13], thus disturbing the stability of the whole structure. Moreover, adoption of local stiffeners and gusset plates, produced excessive welding quantity [14-17] damaging the economic and constructional balance of the global system along with its aesthetic appeal. Therefore, to further improve the behaviour of such open-to-hollow connections and avoid isolated local distortions, several researches implemented the "passing-through" concept. Detailed analytical studies were performed by Alostaz and Schneider [18] on the moment-rotation behaviour of six different open section-to-CHS column connection types, where the through connection provided the most favorable inelastic connection behaviour as it minimized the local distortions occurring in the CHS column wall. Kosteski and Packer [19, 20] and Kosteski [21] investigated longitudinal "through" plate-to-RHS connections and compared their behaviour to similar branch plate-to-RHS connections using experimental as well as numerical prototypes. The through plate-to-RHS connections were built by slotting the plate through the RHS chord and welding the former to both the top and the bottom face of the later. The authors concluded that the design equation for chord plastification of a conventional (branch) plate-to-RHS connection against tensile/compressive forces could be doubled for a through plate-to-RHS connection. This design equation was therefore incorporated in the CIDECT Design guides [9]. A preliminary experimental campaign was conducted by Willibald et al. [22] and Zhao [23] to study the behaviour of longitudinal and transverse through plate-toelliptical hollow section (EHS) connections. These authors also compared different types of through connections with similar branch type connections and obtained almost 1.65-1.96 times greater connection capacity using the "passing-through" approach. Mirghaderi et al. [24] depicted the force transfer mechanism of connections constructed by a vertical plate passing through a RHS (box) column and welded to the column flanges. The authors also suggested a design approach to determine the dimensions of the through plate and other pertinent parts based on an effective load transfer between the beam and column by in-plane actions of the passing plate. Voth $[25,26]$ conducted a comparison study between the conventional (branch) plate-toCHS connections and "passing through" connections (Fig. 1) against transverse tensile/compressive forces with experimental as well as numerical investigations. Hoang et al. [27] studied a through plate-to-CHS column connection where a through vertical plate was used to support the primary beams. Two horizontal plates, one at each side of the CHS, were welded to the upper side of the through-plate to facilitate the connection. The through-plate component was investigated under hogging moment and shear force through experimental and numerical programs. Finally the authors proposed a standard design guide for the aforementioned component. The state of the art research studies were summarized in a review article in a more detailed manner [28].

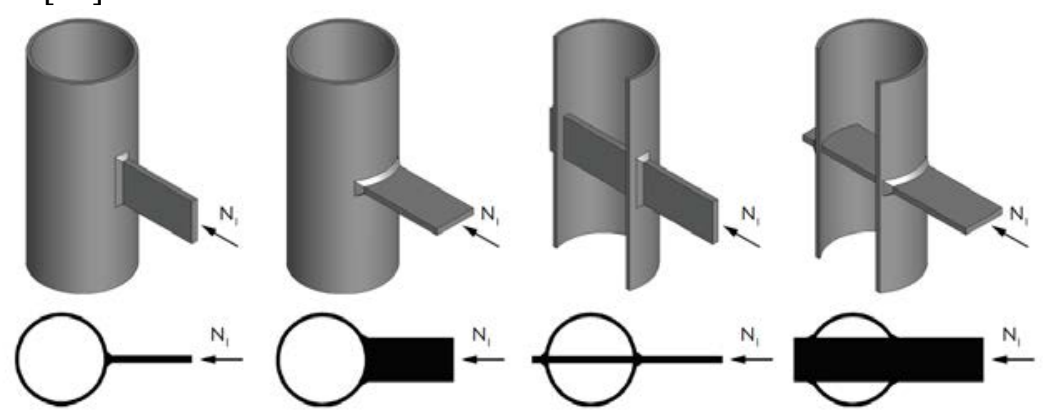


Fig. 1. Different connection configurations studied by Voth [26]

Although these studies show promising results regarding the "passing-through" concept, most of them are dealing with the behavior of the joint loaded by pure axial forces i.e. resistance of the chord face when a tensile/compressive force is applied on the through member. As a result, the possibility to design a moment resisting open-to-CHS connection using a combination of through plates remains an open issue. In this case, a comprehensive study is needed to understand the global behaviour of such connections. This research article aims at filling this gap. Furthermore, practical difficulties regarding the mechanical cutting process, fabrication as well as control of the tolerance also seems to remain an open question [28]*. This study therefore aims at solving this practical limitation in the implementation of "passing-through" design solutions by using the Laser Cutting Technology (LCT), which offers several advantages compared to the conventional mechanical cutting procedure like increasing the fatigue strength [29], reducing the welding quantities, minimizing human errors with computer-programmed automation and offering a swift fabrication process, hence providing an efficient framework to further investigate the "passing-through" connections [30]. The advantages offered by the LCT, the aforementioned potential of the "passing-through" connections and the possibility to design moment-resisting connections with through plates constitutes the bases of the present research study.

In order to achieve a better moment resistance than the conventional open-to-CHS connections, several types of two-way and four-way rigid connections were investigated in the "LASTEICON" research project using the "passing-through" approach, funded by the European Commission [31]. Primarily, the twoway moment resisting connection was constructed with a steel I-beam stub passing through a steel CHS column via LCT slots (Fig. 2a). "Main" load carrying beams were connected to the through I-beam via flange and web connector plates. Local distortions in the CHS column as well as unnecessary use of gusset plates (or stiffeners) were efficiently avoided as encouraging results were found through extensive parametric investigations. Standard design guidelines were therefore developed and recommended for practical implementation of such connections. However, possible areas were noticed for further improvement. Constructing the four-way connections were deemed almost impossible only with through I-beams, as a proficient connection could not be obtained by passing one I-beam stub through another [31]. In these cases, individual flange (horizontal) and web (vertical) plates seemed to be a far better solution where the "main" beams are connected to a through I-beam in one-direction and individual plates in the other (Fig. $2 \mathrm{~b}$ ) i.e. the orthogonal direction. Easy positioning and better precision in terms of tolerances could be obtained for the through plates compared to the second through I-beam stub. Relevant details regarding the complete fabrication process applied to the different types of LASTEICON joints were discussed in a first study [30]. However, using through plates from two orthogonal directions might cause instability issues and are therefore not recommended.

(a)

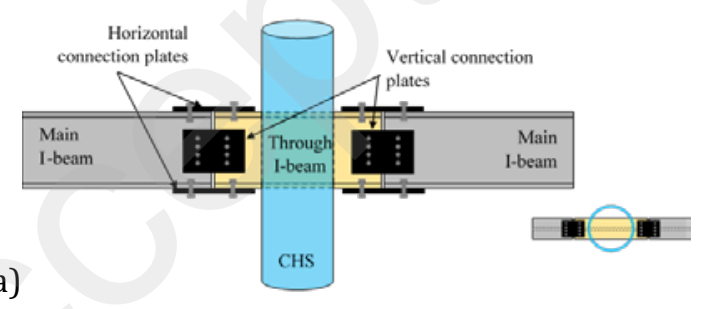

(b)

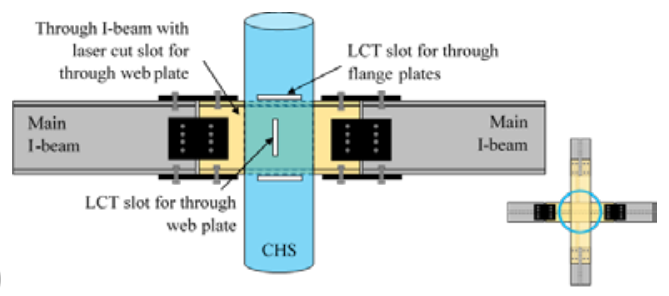

Fig. 2. (a) two-way connection with I-beam passing through the CHS, (b) four-way connection with I-beam passing through the CHS on one direction and individual plates on another

Constructional costs can also be minimized by using steel plates instead of a steel I-beam. Therefore, due to these added benefits, an alternative moment resisting connection configuration has been proposed in the LASTEICON research project and is discussed in this present study. This connection consists of three individual plates (two horizontal flange plates and a vertical web plate) passing through the CHS column via LCT slots made on the CHS column, where the "main" I-beams are connected to both ends of the passing 
through members (named as "through" members) as shown in Fig. 3. The applied moment is effectively transferred by the through plates to the CHS column, whereas, the CHS column contributes significantly in resisting it through its resistance against transverse tensile/compressive forces. This study investigates the proposed LASTEICON connection through several design calculations further validated by experimentally calibrated numerical FE models with a primary objective to identify and characterize their behavioral aspects and thus propose a constructive design approach for future designers to determine their ultimate resistance. As a detailed perspective for such connections is still not available with complete details, this present investigation can be identified as the first step to develop preliminary design guidelines for such "passingthrough" plate-to-CHS connections with experimental studies planned in the near future to provide necessary real life evidences.

(a)

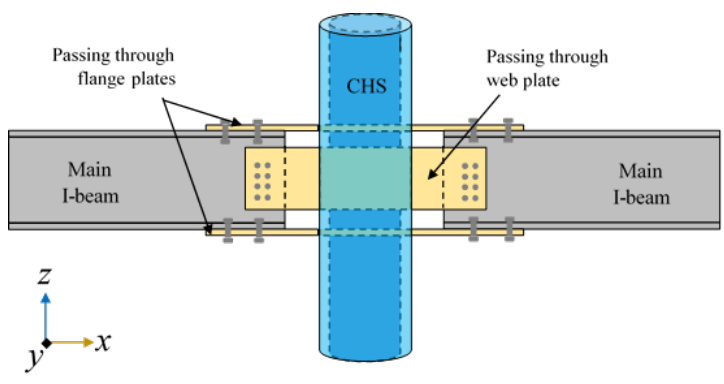

(b)

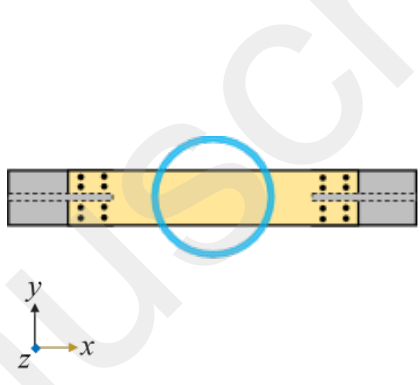

Fig. 3. Schematic diagram of the proposed LASTEICON connection showing (a) frontal view and (b) top view

\section{DESIGN APPROACH FOR THE LASTEICON MOMENT RESISTING CONNECTION WITH STEEL PLATES PASSING THROUGH A CHS COLUMN}

A new design approach was proposed for this LASTEICON connection, based on the available literature $[1,12]$ and the numerical parametric studies validated through experimental tests. As this study primarily focused upon deriving the "passing-through" joint, the bolting connections between the "through" plates and "main" beams were assumed to be overstrengthened to avoid any secondary connection failure occurring due to their breakage and were thus modified into a perfectly welded plate connection (further discussed in Section 3). Two different load cases, a gravitational loading scenario, LC1 (Fig. 4a); and an opposite bending loading, LC2 (Fig. 4b); were considered to gather a detailed understanding of the moment connection behaviour. Therefore, two different design procedures were derived for two different loading scenarios. Fig. 5 shows a schematic diagram of the proposed LASTEICON connection with the entitled parameters used in the design procedures.

(a)

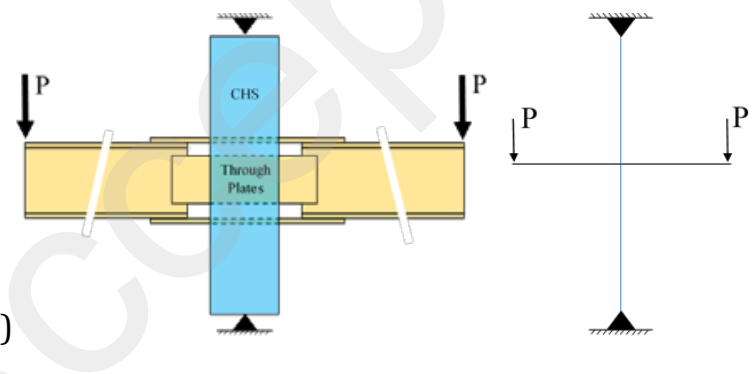

(b)

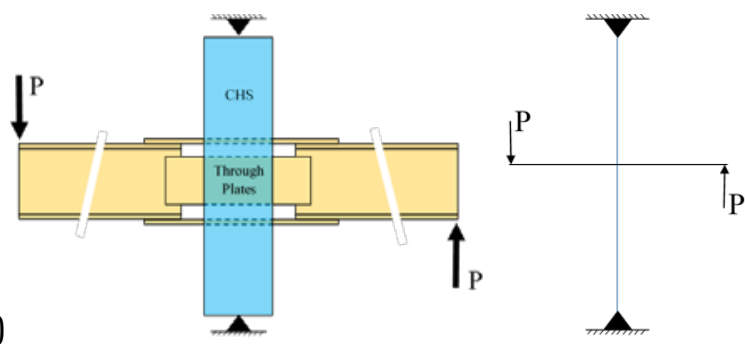

Fig. 4. Loading Conditions: (a) LC1-Monotonic gravitational and (b) LC2-Monotonic opposite bending loading

\subsection{Design flexural resistance of the LASTEICON connection}

In an unstiffened and conventionally welded Plate-to-CHS connections, the steel tube is subjected to high local distortions adjacent to the connected region and generally fails due to chord face yielding independent of the loading conditions. Whereas, in the through connections, different force-transfer mechanisms were identified depending upon the loading conditions. 


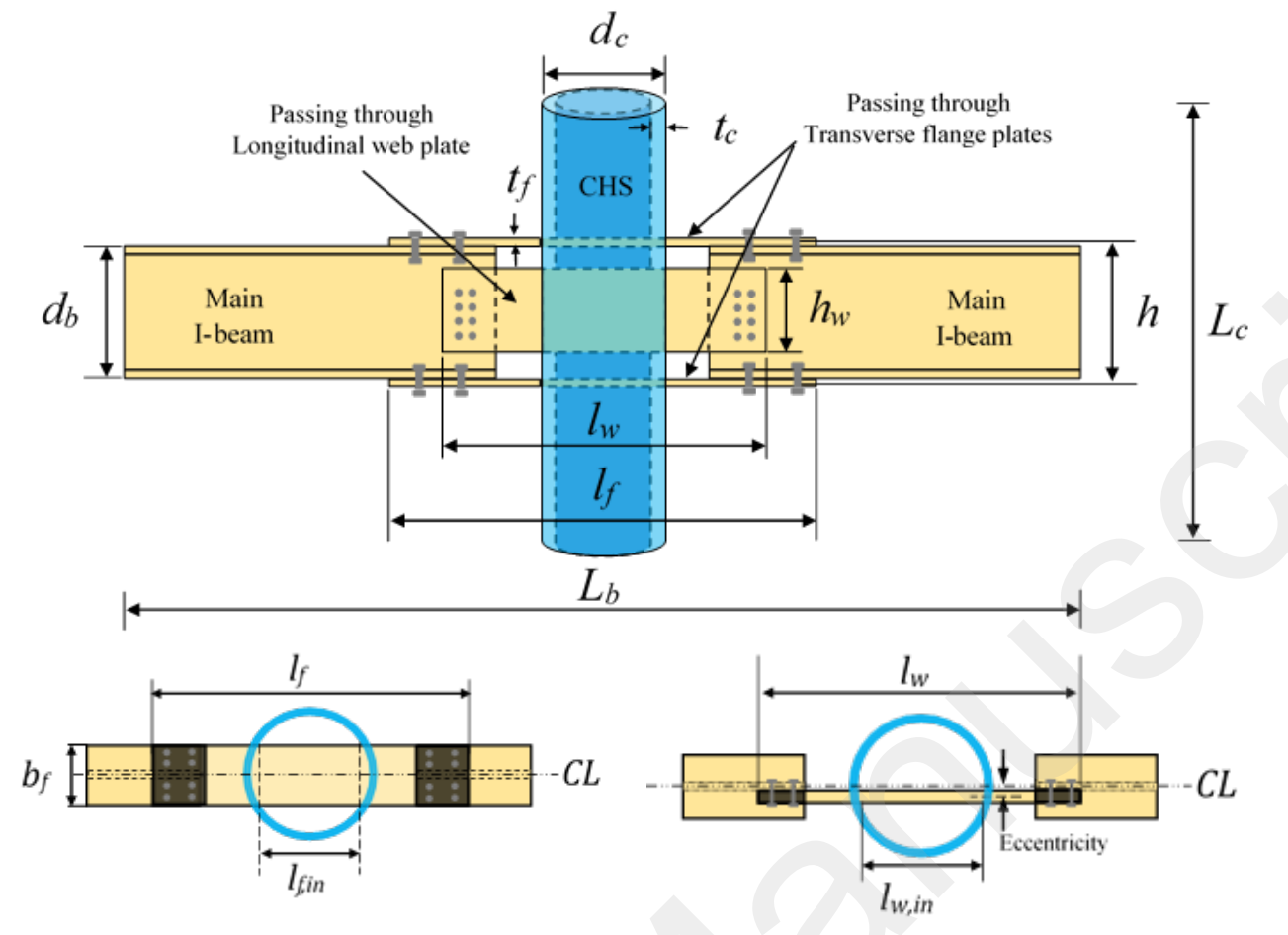

Fig. 5. Schematic diagram of the proposed LASTEICON connection with important design parameters

\subsubsection{Monotonic gravitational loading, LC1}

Under a gravitational or symmetric loading condition LC1, the moment $\left(M_{b, s y m}\right)$ at the "passing-through" joint can be resolved into tensile $\left(T_{f}\right)$ and compressive forces $\left(C_{f}\right)$ on the flange plates as shown in Fig. 6a. These forces are primarily resisted by the through flange plates. As the flange plates are rather vulnerable towards compressive stresses, a severe chance of buckling was recognized and was thus validated by the numerical studies. Hence, the design procedure under LC1 was developed based on the buckling resistance of the through flange plate under compression as indicated in Fig. $6 \mathrm{~b}$.

(a)

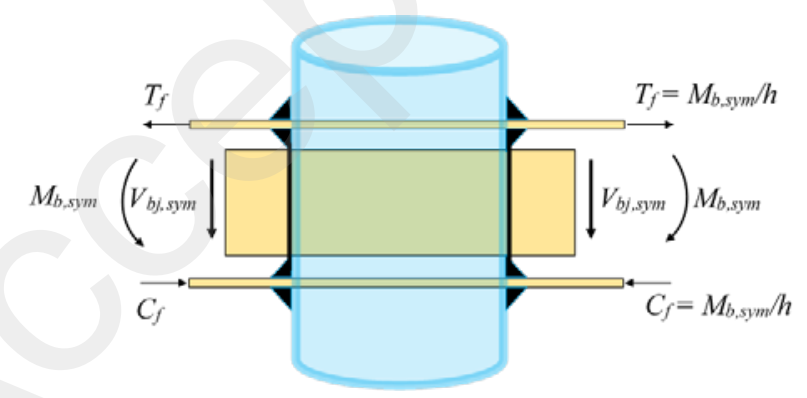

(b)

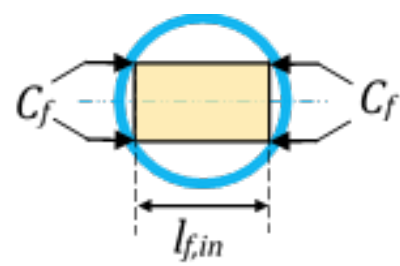

(c)

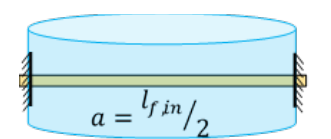

Fig 6. (a) Free body diagram of forces at joint panel boundaries under symmetric loading (LC1), (b) Free body diagram of forces indicating the assumption of minimum through flange plate length, (c) assumed fixed-fixed boundary condition to determine the critical buckling length of the through flange plate

According to a "column type buckling behaviour" proposed by EN 1993-1-5, Clause 4.5 .3 [32], the elastic critical buckling stress of the through flange plate can be derived as, 
$\sigma_{c r, c}=\frac{\pi^{2} E t_{f}^{2}}{12\left(1-v^{2}\right) a^{2}}$

Where, $\mathrm{E}$ is the Young's modulus, $\mathrm{v}$ is the Poisson's ration, $t_{f}$ is the thickness of the flange plate, $a$ is the critical buckling length. The proposed connections are designed in such a way that the through flange plates are perfectly welded to the CHS column surface. So, both sides of the plate can be assumed as fixed and the critical buckling length, $a$, can therefore be derived as,

$a=\frac{l_{f, i n}}{2}=\frac{2 \cdot \sqrt{\left\{0.5\left(d_{c}-2 t_{c}\right)\right\}^{2}-\left\{0.5 b_{f}\right\}^{2}}}{2}$

Where, $l_{f, i n}$ is the minimum length of the through flange plate inside the CHS (Fig. $6 \mathrm{~b}$ ), $b_{f}$ is the width of the through flange plate, $d_{c}$ is the diameter of the CHS column and $t_{c}$ is the thickness of the CHS column as shown in Fig 5. After $\sigma_{c r, c}$ is calculated from Eq. 1, the relative column slenderness $\left(\lambda_{c}\right)$ can be calculated according to the EN 1993-1-5 guidelines for unstiffened plates,

$\lambda_{c}=\sqrt{\frac{f_{y}}{\sigma_{c r, c}}}$

Where $f_{y}$ is the material yield strength. The reduction factor $(\chi)$ should then be calculated according to Clause 6.3.1.2 of EN 1993-1-1 [33] with $\alpha=0.21$ as recommended by EN 1993-1-5, Clause 4.5.3(5).

$\chi=\frac{1}{\Phi+\sqrt{\Phi^{2}-\lambda_{c}^{2}}}$

Where, $\Phi=0.5\left[1+\alpha\left(\lambda_{c}-0.2\right)+\lambda^{2}\right]$. Therefore, the design buckling resistance $\left(N_{b, R d}\right)$ of the through flange plate can be finally determined according to EN 1993-1-1, Clause 6.3.1(3) as follows,

$N_{b, R d}=\frac{\chi b_{f} t_{f} f_{y}}{\gamma_{M 1}}$

Therefore, assuming that the maximum allowable tensile force $\left(T_{f}\right)$ is equal to the maximum allowable compressive force $\left(C_{f}=N_{b, R d}\right)$ and the bending moment is carried entirely by the flanges, the flexural resistance of the joint under a symmetric loading can be calculated as,

$M_{b, R d, s y m}=N_{b, R d} h$

Where $h$ is the distance between the centers of the top and bottom through flange plates (Fig. 5).

\subsubsection{Monotonic opposite bending loading, LC2}

Under an opposite bending or antisymmetric loading condition (Fig. 4b), the force-transfer mechanism can be visualized from the free body diagram illustrated in Fig. 7a. The beam moments are similarly resolved into flange forces, $T_{f}$ and $C_{f}$. Based on the extensive numerical parametric studies, the transverse shear resistance of the through web plate and the transverse tensile/compressive resistance of the CHS column wall were recognized as the primary resistances against $T_{f}$ and $C_{f}$ under an opposite bending loading scenario. Therefore, this newly proposed design procedure was developed accordingly to determine the flexural strength of the 
joint under opposite bending. Assuming that the beam bending moment is carried by the whole sections of flanges, the tensile and compressive forces in the beam flange, $T_{f}$ and $C_{f}$, can be estimated as:

$$
T_{f}=C_{f}=\frac{M_{b, o p p}}{h}
$$

Where, $M_{b, o p p}$ is the moment demand at either side of the connection. The column shear transferred through the joint increases the joint shear strength by reducing the beam flange forces transferred to the joint. Therefore, referring to Fig. $7 \mathrm{~b}$, the effective horizontal shear force acting on the joint panel, $V_{u}$, can thus be written as,

$$
V_{u}=\frac{2 M_{b, o p p}}{h}-V_{c}
$$

(a)

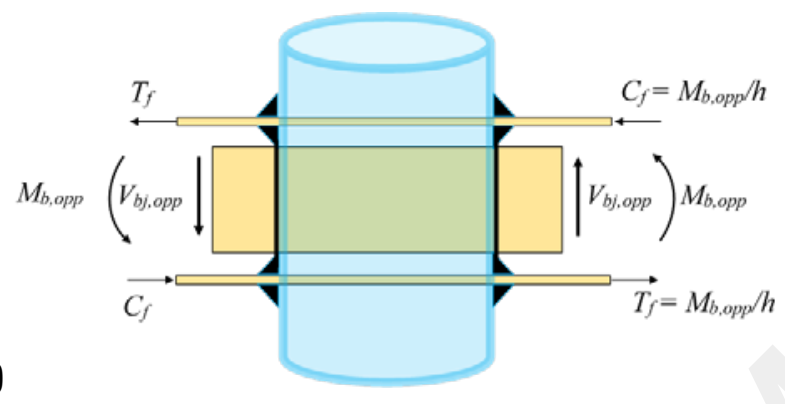

(b)

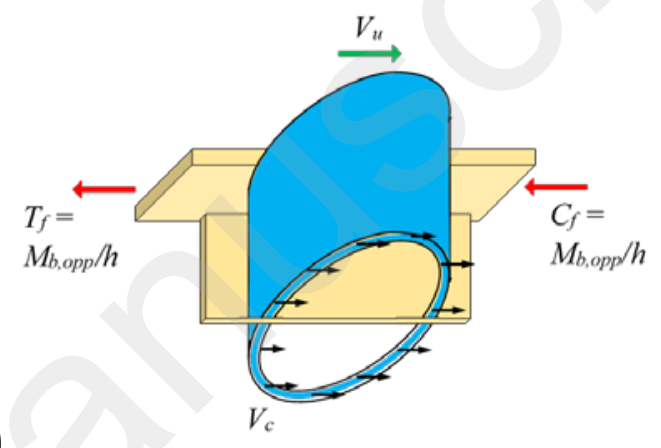

Fig 7. (a) Free body diagram of forces at joint panel boundaries under antisymmetric loading (LC2), (b) 3D view of the joint panel cut in half

This horizontal shear force acting on the joint is resisted by the shear strength of the through web plate, $V_{w n}$; and the in-plane moment resistance of the CHS column wall, $M_{i p, 1, R d}$. The $M_{i p, 1, R d}$ is defined as the design inplane moment resistance of the CHS column wall according to EN 1993-1-8, Table 7.4 for X-type joints [34] and is derived from the transverse tensile/compressive resistance of the CHS chord face, $N_{1, R d}$. However, contrary to the conventional connections, both the inner as well as the outer wall of the CHS column offers resistance thanks to the passing through elements (Fig. 8a) and thus doubles the resistance. Therefore, the $M_{i p, 1, R d}$ value suggested for the Branch-type (conventional) connections were doubled to associate the increased resistance according to the guidelines for passing though connections provided by the latest draft of EN 1993-1-8, Table 7.4 [35].

(a)

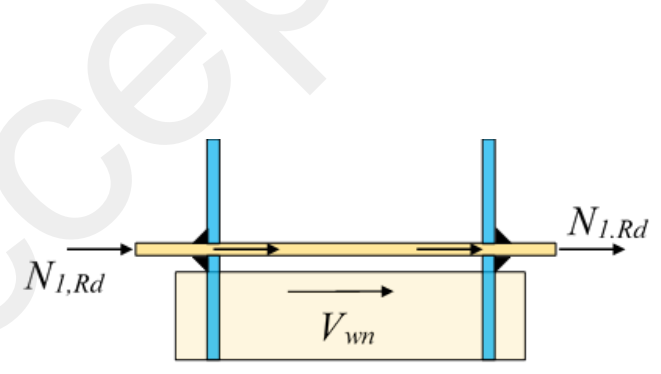

(b)

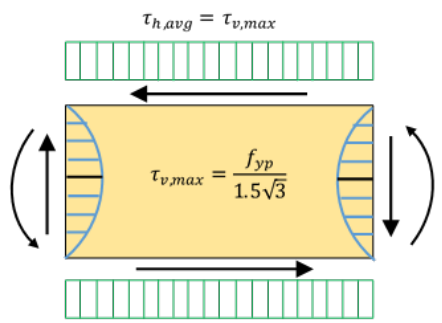

Fig 8. (a) Equilibrium of horizontal forces at the joint panel under antisymmetric loading (LC2), (b) $2 D$ view of the shear stress distribution in the through web plate inside the CHS column

The complete joint capacity is achieved when all contributing mechanisms have reached their individual shear strengths. Thus, the total resistance, $V_{n}$, can be calculated as expressed in Eq. 9. 


$$
V_{n}=V_{w n}+V_{c n}
$$

Where,

$V_{w n}=\tau_{v, \max } l_{w, i n} t_{w}$

$V_{c n}=\frac{M_{i p, 1, R d}}{h}$

Where maximum shear stress, $\tau_{v, \max }=\frac{\tau_{v, a v g}}{1.5}=\frac{f_{y W P}}{1.5 \sqrt{3}}, f_{y W P}$ is the material yield stress of the through web plate, $l_{w, i n}$ is the minimum length of the through web plate inside the CHS column and $t_{w}$ is the thickness of the through web plate as shown in Fig. 5. As shown in Fig. 8b, the stress distribution along the vertical axis of the through web plate was identified to be a parabolic distribution rather than a uniform rectangular one. This phenomenon limited the shear resistance of the through web plate in the longitudinal direction and therefore $\tau_{\text {avg }}$ was realized to be too optimistic in determining the strength of such LASTEICON connections. Therefore, the shear resistance provided by the through web plate is calculated based on the maximum shear stress, $\tau_{\max }$ acting over the web area within the joint panel to recommend a safe and reliable design. This assumption is further discussed in Section 4.4 with FE simulation results. Therefore, the flexural resistance of the LASTEICON joint can be calculated as,

$M_{b, R d, o p p}=\left(V_{n}+V_{c}\right) \frac{h}{2}$

\subsubsection{Checks for additional failure modes}

Other than the failure of the joint, three additional failure modes can occur due to the bending forces. To ensure safety against such undesired failure, three checks are needed as described below. However, as discussed earlier, two different force-transfer mechanisms were identified depending upon the loading scenarios. As a result, the checks also depend upon the loading scenario. Based upon the comprehensive parametric study discussed in the later sections, it was seen that only Check 1 is necessary for the gravitational loading, LC1, while Check 1, 2 and 3 are necessary for the opposite bending loading, LC2.

\section{Check 1: Check for flexural failure of main beams:}

When the joint offers a higher resistance than the main beams, possibility rises for a second type of failure due to flexural plasticity in the main beams. Therefore, the flexural resistance of the main beams $\left(M_{p l, R d, B e a m}\right)$ should be calculated according to EN 1993-1-1 [33] and checked at the center of the through plate-to-main beam connection i.e. at a distance of $0.5\left\{l_{w}+\left(l_{f}-l_{w}\right) / 2\right\}$ from the central axis of the CHS column (Fig. 5).

\section{Check 2: Check for local buckling of the CHS column:}

Although, CHS members are not deemed to be vulnerable against lateral instability, certain conditions should be followed to avoid premature local buckling. Firstly, the CHS should be classified according to Table 5.2 of EN 1993-1-1 based on the diameter-to-thickness ratio. Furthermore, if a CHS is found to be a Class 3 or Class 4 type hollow section, their flexural resistance, $M_{R d, C H S}$, should be checked to avoid any possibility of local buckling [36],

For Class 3 sections: $\quad M_{R d, C H S}=\frac{W_{e l, C H S} f_{y c}}{\gamma_{m 0}}$

For Class 4 sections: $\quad M_{R d, C H S}=\frac{W_{e f f, C H S} f_{y c}}{\gamma_{m 0}}$

Where, $W_{\text {el, СHS }}$ and $W_{\text {eff, CHS }}$ are respectively defined as the elastic section modulus and effective section modulus of the CHS and can be calculated according to EN 1993-1-1. To avoid such a failure, the flexural resistance of the CHS columns $\left(M_{R d, C H S}\right)$ should be checked at the connection level. Furthermore, it is recommended to avoid 
slender CHS columns (Class 3 and Class 4 hollow sections) in such LASTEICON joints. This can be done simply by using the first step of this design check i.e. classification according to the EN 1993-1-1.

\section{Check 3: Check for punching shear failure:}

A further check is also suggested in accordance with the EN 1993-1-8 [34] and CIDECT guidelines [12] to avoid punching shear failure of the CHS column wall. According to the available design guidelines, the check is only needed if,

$b_{f} \leq d_{c}-2 t_{c}$

And if required, the following restriction should be respected.

$f_{b} t_{f} \leq 1.16 f_{y c} t_{c}$

Where, $b_{f}$ is the width and $t_{f}$ is the thickness of the through flange plate, $d_{c}$ and $t_{c}$ are the diameter and thickness of the CHS column and $f_{b}$ is the stress at which the punching shear occurs on the CHS column wall. So, if $M_{b p}$ is the bending moment produced due to $f_{b}$, then,

$M_{b p}=f_{b} W_{e l, s e c}$

Where $W_{\text {el,sec }}$ is the elastic section modulus of the section formed by the three passing through plates. Therefore, to avoid such a failure, the joint strength $M_{b, o p p}$ should be greater than or at least equal to $M_{b p \text {. }}$

\subsubsection{Correlation to the global configuration}

The abovementioned design procedures determine the resistance of the passing through joint from a local perspective. However, in order to correlate the design procedure to the numerical and experimental prototypes and further compare the analytical results with the numerical simulations, the joint strengths should be calculated in terms of the shear force developed due to the vertical loads acting at the extremities of the "main" beams. Therefore, if $P$ is the vertical load at the free end of the "main" beam and $V_{b j}$ is the corresponding shear developed on the beam at the location of the CHS column face (Fig. 6 and 7),

$P=V_{b j}=\frac{M_{b}}{\left(L_{b}-d_{c}\right) / 2}$

Where, $V_{b j}$ and $M_{b}$ are respectively equal to $V_{b j, s y m}$ and $M_{b, s y m}$ under a symmetric loading; $V_{b j, o p p}$ and $M_{b, o p p}$ under an opposite bending loading scenario. In the through beam connection detail, it is reasonable to consider that the entire column shear is effective in reducing joint shear forces since the column is continuous through the joint and is directly attached to the beam through proper welds. This makes the joint strength dependent on the global configuration and the column shear $\left(V_{c}\right)$ can be calculated from,

$V_{c}=P \frac{L_{b}}{L_{c}}=\frac{M_{b}}{\left(L_{b}-d_{c}\right)} \frac{2 L_{b}}{L_{c}}$

Therefore, the joint flexural resistance derived in Eq. 12 can be rewritten as,

$M_{b, R d, o p p}=\frac{\left(V_{w n}+V_{c n}\right) / 1.1}{\left[\frac{2}{h}-\frac{2 L_{b}}{L_{c}}\left(\frac{1}{L_{b}-d_{c}}\right)\right]}$ 
Where, a safety factor of 1.1 is suggested by comparison with the American Institute of Steel Construction (AISC) LRFD approaches for similar types of connections [30]. Furthermore, $M_{b, o p p}$ can be derived in terms of $V_{b j}$ following Eq. 18. Similar expressions were also derived in terms of shear corresponding to the moments for all checks under LC1 and LC2. To avoid such undesired failures mentioned in the previous sections,

\section{Check for flexure failure of the main beams:}

$V_{b j, \text { sym or opp }}\left(=\frac{M_{b, R d, \text { sym or opp }}}{\left(L_{b}-d_{c}\right) / 2}\right)<V_{b b}\left(=\frac{M_{p l, R d, \text { Beam }}}{\left[L_{b}-\left\{l_{w}+\left(\frac{l_{f}-l_{w}}{2}\right)\right\}\right] / 2}\right)$

\section{Check for local buckling of the CHS column:}

$V_{b j, o p p}\left(=\frac{M_{b, R d, o p p}}{\left(L_{b}-d_{c}\right) / 2}\right)<V_{b c}\left(=\frac{M_{R d, C H S}}{\left(L_{c}-h\right) / 2}\left(\frac{L_{c}}{L_{b}}\right)\right)$

Check 3: Check for punching shear failure:

$V_{b j, o p p}\left(=\frac{M_{b, R d, o p p}}{\left(L_{b}-d_{c}\right) / 2}\right)<V_{b p}\left(=\frac{M_{b p}}{\left(L_{b}-d_{c}\right) / 2}\right)$

As a detailed parametric study is carried over in this present investigation, the minimum value of all relevant $V_{b j}$ values for a given loading condition is considered as the shear force corresponding to the ultimate strength of the LASTEICON joint. Therefore, to identify the probable failure mode, $V_{b u}\left(V_{b u, \text { sym }}\right.$ under $L C 1$ and $V_{b u, o p p}$ under $L C 2$ ) is considered as,

$$
\begin{aligned}
& V_{b u, s y m}=\min \left(V_{b j, s y m}, V_{b b}\right) \\
& V_{b u, o p p}=\min \left(V_{b j, o p p}, V_{b b}, V_{b c}, V_{b p}\right)
\end{aligned}
$$

Table 1 and 2 lists all the parametric variations along with their ultimate joint strengths calculated according to the proposed design procedures for LC1 and LC2 respectively. Values corresponding to the relevant checks are also provided to show the failure predictions made by the corresponding design procedures.

\subsection{Design shear strength of the LASTEICON connection}

The shear strength of the "passing-through" joint can be simply determined from the shear strength of the through web plate. As mentioned earlier, this is calculated assuming a parabolic distribution of shear stresses along the vertical axis of the through web plate,

$V_{\text {joint }}=\tau_{v, \max } h_{w} t_{w}=\frac{f_{y b}}{1.5 \sqrt{3}} \frac{h_{w} t_{w}}{\gamma_{m 0}}$

Where, $h_{w}$ is the depth and $t_{w}$ is the thickness of the through web plate. However, as the shear strength of the configurations were obtained to be much higher than the flexural strength of the connections under both loading conditions, these values were not listed further. 
Table 1: Analytical values corresponding to the ultimate joint strength under LC1, $V_{b u, s y m}{ }^{2}$

\begin{tabular}{|c|c|c|c|c|c|c|c|c|c|}
\hline \multirow{2}{*}{$\begin{array}{l}\text { Varying } \\
\text { Parameters }\end{array}$} & \multirow[b]{2}{*}{$\begin{array}{r}a \\
(\mathrm{~mm}) \\
\end{array}$} & \multirow[b]{2}{*}{$\chi_{f}$} & \multirow[b]{2}{*}{$\begin{array}{l}N_{b, R d} \\
(\mathrm{kN})\end{array}$} & \multicolumn{2}{|c|}{$\begin{array}{l}\text { Through Flange } \\
\text { Plate buckling }\end{array}$} & \multicolumn{2}{|c|}{$\begin{array}{l}\text { Check: "Main" beam } \\
\text { flexural failure }\end{array}$} & \multirow{2}{*}{$\begin{array}{r}\begin{array}{r}\text { Joint Ultimate } \\
\text { Strength }\end{array} \\
V_{b u, s y m} \\
(\mathrm{kN})\end{array}$} & \multirow{2}{*}{ Failure Mode } \\
\hline & & & & $\begin{array}{c}M_{b, R d, s y m} \\
(\mathrm{kNm})\end{array}$ & $\begin{array}{r}V_{b j, s y m} \\
(\mathrm{kN})\end{array}$ & $\begin{array}{r}M_{p l, R d, \text { Beam }} \\
(\mathrm{kNm})\end{array}$ & $\begin{array}{r}V_{b b} \\
(\mathrm{kN})\end{array}$ & & \\
\hline \multicolumn{10}{|c|}{ For CHS Thickness variation, $t_{c}$} \\
\hline 4.0 & 148.7 & 0.896 & 813.1 & 335.0 & 144.3 & 548.9 & 258.9 & 144.3 & Plate Buckling in Compression \\
\hline 6.0 & 146.3 & 0.900 & 816.2 & 336.3 & 144.8 & 548.9 & 258.9 & 144.8 & Plate Buckling in Compression \\
\hline 8.0 & 144.0 & 0.903 & 819.1 & 337.5 & 145.3 & 548.9 & 258.9 & 145.3 & Plate Buckling in Compression \\
\hline 10.0 & 141.6 & 0.906 & 822.1 & 338.7 & 145.9 & 548.9 & 258.9 & 145.9 & Plate Buckling in Compression \\
\hline 12.5 & 138.7 & 0.910 & 825.7 & 340.2 & 146.5 & 548.9 & 258.9 & 146.5 & Plate Buckling in Compression \\
\hline \multicolumn{10}{|c|}{ For CHS Diameter variation, $d_{c}$} \\
\hline 273.0 & 88.9 & 0.966 & 876.2 & 361.0 & 152.7 & 548.9 & 258.9 & 152.7 & Plate Buckling in Compression \\
\hline 323.9 & 122.4 & 0.930 & 844.0 & 347.7 & 148.7 & 548.9 & 258.9 & 148.7 & Plate Buckling in Compression \\
\hline 355.6 & 141.6 & 0.906 & 822.1 & 338.7 & 145.9 & 548.9 & 258.9 & 145.9 & Plate Buckling in Compression \\
\hline 375.0 & 153.0 & 0.890 & 807.4 & 332.7 & 143.9 & 548.9 & 258.9 & 143.9 & Plate Buckling in Compression \\
\hline 406.4 & 171.0 & 0.861 & 781.3 & 321.9 & 140.2 & 548.9 & 258.9 & 140.2 & Plate Buckling in Compression \\
\hline \multicolumn{10}{|c|}{ For Flange Plate thickness variation, $t_{f}$} \\
\hline 12.0 & 141.6 & 0.906 & 822.1 & 338.7 & 145.9 & 548.9 & 258.9 & 145.9 & Plate Buckling in Compression \\
\hline 14.0 & 141.6 & 0.932 & 986.0 & 408.2 & 175.8 & 548.9 & 258.9 & 175.8 & Plate Buckling in Compression \\
\hline 16.0 & 141.6 & 0.948 & 1147.2 & 477.2 & 205.5 & 548.9 & 258.9 & 205.5 & Plate Buckling in Compression \\
\hline 18.0 & 141.6 & 0.960 & 1307.0 & 546.3 & 235.3 & 548.9 & 258.9 & 235.3 & Plate Buckling in Compression \\
\hline 20.0 & 141.6 & 0.970 & 1466.0 & 615.8 & 265.2 & 548.9 & 258.9 & 258.9 & Main Beam flexure \\
\hline \multicolumn{10}{|c|}{ For Web Plate thickness variation, $t_{w}$ with Low Flange Thickness (LFT) $\left(t_{f}=12 \mathrm{~mm}\right)$} \\
\hline 10.0 & 141.6 & 0.906 & 822.1 & 338.7 & 145.9 & 548.9 & 258.9 & 145.9 & Plate Buckling in Compression \\
\hline 12.0 & 141.6 & 0.906 & 822.1 & 338.7 & 145.9 & 548.9 & 258.9 & 145.9 & Plate Buckling in Compression \\
\hline 14.0 & 141.6 & 0.906 & 822.1 & 338.7 & 145.9 & 548.9 & 258.9 & 145.9 & Plate Buckling in Compression \\
\hline 16.0 & 141.6 & 0.906 & 822.1 & 338.7 & 145.9 & 548.9 & 258.9 & 145.9 & Plate Buckling in Compression \\
\hline 18.0 & 141.6 & 0.906 & 822.1 & 338.7 & 145.9 & 548.9 & 258.9 & 145.9 & Plate Buckling in Compression \\
\hline \multicolumn{10}{|c|}{ For Web Plate thickness variation, $t_{w}$ with High Flange Thickness (HFT) $\left(t_{f}=20 \mathrm{~mm}\right)$} \\
\hline 10.0 & 141.6 & 0.970 & 1466.0 & 615.8 & 265.2 & 548.9 & 258.9 & 258.9 & Main Beam flexure \\
\hline 12.0 & 141.6 & 0.970 & 1466.0 & 615.8 & 265.2 & 548.9 & 258.9 & 258.9 & Main Beam flexure \\
\hline 14.0 & 141.6 & 0.970 & 1466.0 & 615.8 & 265.2 & 548.9 & 258.9 & 258.9 & Main Beam flexure \\
\hline 16.0 & 141.6 & 0.970 & 1466.0 & 615.8 & 265.2 & 548.9 & 258.9 & 258.9 & Main Beam flexure \\
\hline 18.0 & 141.6 & 0.970 & 1466.0 & 615.8 & 265.2 & 548.9 & 258.9 & 258.9 & Main Beam flexure \\
\hline
\end{tabular}

For varying Moment-to-shear (M/V) ratio by varying beam length $\left(L_{b}\right)$ with LFT $\left(t_{f}=12 \mathrm{~mm}\right)$

\begin{tabular}{l|rrrrr|r|r|r|l}
\hline 2500.0 & 141.6 & 0.906 & 822.1 & 338.7 & 315.9 & 548.9 & 631.0 & 315.9 & Plate Buckling in Compression \\
3400.0 & 141.6 & 0.906 & 822.1 & 338.7 & 222.5 & 548.9 & 415.9 & 222.5 & Plate Buckling in Compression \\
5000.0 & 141.6 & 0.906 & 822.1 & 338.7 & 145.9 & 548.9 & 258.9 & 145.9 & Plate Buckling in Compression \\
6600.0 & 141.6 & 0.906 & 822.1 & 338.7 & 108.5 & 548.9 & 188.0 & 108.5 & Plate Buckling in Compression \\
7500.0 & 141.6 & 0.906 & 822.1 & 338.7 & 94.8 & 548.9 & 162.9 & 94.8 & Plate Buckling in Compression \\
\hline
\end{tabular}

For varying Moment-to-shear (M/V) ratio by varying beam length $\left(L_{b}\right)$ with HFT $\left(t_{f}=20 \mathrm{~mm}\right)$

\begin{tabular}{|c|c|c|c|c|c|c|c|c|c|}
\hline 2500.0 & 141.6 & 0.970 & 1466.0 & 615.8 & 574.3 & 548.9 & 631.0 & 574.3 & Plate Buckling in Compression \\
\hline 3400.0 & 141.6 & 0.970 & 1466.0 & 615.8 & 404.5 & 548.9 & 415.9 & 404.5 & Plate Buckling in Compression \\
\hline 5000.0 & 141.6 & 0.970 & 1466.0 & 615.8 & 265.2 & 548.9 & 258.9 & 258.9 & Main Beam flexure \\
\hline 6600.0 & 141.6 & 0.970 & 1466.0 & 615.8 & 197.2 & 548.9 & 188.0 & 188.0 & Main Beam flexure \\
\hline 7500.0 & 141.6 & 0.970 & 1466.0 & 615.8 & 172.4 & 548.9 & 162.9 & 162.9 & Main Beam flexure \\
\hline \multicolumn{10}{|c|}{ For Material variation $\left(f_{y p} \& f_{y c}\right)$} \\
\hline $275.0 \& 275.0$ & 141.6 & 0.939 & 557.9 & 229.9 & 99.0 & 359.4 & 169.5 & 99.0 & Plate Buckling in Compression \\
\hline $355.0 \& 355.0$ & 141.6 & 0.921 & 706.2 & 291.0 & 125.3 & 464.0 & 218.9 & 125.3 & Plate Buckling in Compression \\
\hline $440.0 \& 440.0$ & 141.6 & 0.902 & 856.9 & 353.1 & 152.0 & 575.1 & 271.3 & 152.0 & Plate Buckling in Compression \\
\hline $420.0 \& 377.0$ & 141.6 & 0.906 & 822.1 & 338.7 & 145.9 & 548.9 & 258.9 & 145.9 & Plate Buckling in Compression \\
\hline $355.0 \& 440.0$ & 141.6 & 0.921 & 706.2 & 291.0 & 125.3 & 464.0 & 218.9 & 125.3 & Plate Buckling in Compression \\
\hline $440.0 \& 355.0$ & 141.6 & 0.902 & 856.9 & 353.1 & 152.0 & 575.1 & 271.3 & 152.0 & Plate Buckling in Compression \\
\hline
\end{tabular}


Table 2: Analytical values corresponding to the ultimate joint strength under LC2, $V_{b u, o p p} 2$

\begin{tabular}{|c|c|c|c|c|c|c|c|c|c|c|}
\hline \multirow{2}{*}{$\begin{array}{l}\text { Varying } \\
\text { Parameters }\end{array}$} & \multicolumn{3}{|c|}{$\begin{array}{r}\text { Joint } \\
\text { Flexural Strength }\end{array}$} & \multirow{2}{*}{$\begin{array}{r}\begin{array}{r}\text { Check 1: } \\
\text { Beam flexure }\end{array} \\
V_{b b} \\
(\mathrm{kN}) \\
\end{array}$} & \multirow{2}{*}{$\begin{array}{r}\text { Check 2: } \\
\text { Local buckling } \\
V_{b c} \\
(\mathrm{kN})\end{array}$} & \multicolumn{3}{|c|}{$\begin{array}{r}\text { Check 3: } \\
\text { Punching Shear }\end{array}$} & \multirow{2}{*}{$\begin{array}{r}\begin{array}{r}\text { Joint } \\
\text { Ultimate Strength }\end{array} \\
V_{b u, o p p} \\
(\mathrm{kN})\end{array}$} & \multirow{2}{*}{ Failure mode } \\
\hline & $\begin{array}{r}V_{w n} \\
(\mathrm{kN})\end{array}$ & $\begin{array}{r}V_{c n} \\
(\mathrm{kN})\end{array}$ & $\begin{array}{l}V_{b j, o p p} \\
(\mathrm{kN})\end{array}$ & & & $\begin{array}{r}f_{b} \\
\left(\mathrm{~N} / \mathrm{mm}^{2}\right)\end{array}$ & $\begin{array}{r}M_{b p} \\
(\mathrm{kNm})\end{array}$ & $\begin{array}{r}V_{b p} \\
(\mathrm{kN})\end{array}$ & & \\
\hline \multicolumn{11}{|c|}{ For CHS Thickness variation, $t_{c}$} \\
\hline 4.0 & 582.0 & 102.2 & 67.4 & 258.9 & 70.3 & 145.8 & 162.2 & 69.8 & 67.4 & Joint Panel Shear \\
\hline 6.0 & 575.2 & 230.0 & 79.3 & 258.9 & 103.7 & 218.7 & 243.3 & 104.8 & 79.3 & Joint Panel Shear \\
\hline 8.0 & 568.5 & 409.0 & 96.3 & 258.9 & 135.9 & 291.5 & 324.4 & 139.7 & 96.3 & Joint Panel Shear \\
\hline 10.0 & 561.8 & 639.0 & 118.3 & 258.9 & 218.7 & 364.4 & 405.4 & 174.6 & 118.3 & Joint Panel Shear \\
\hline 12.5 & 553.3 & 998.4 & 152.9 & 258.9 & 269.4 & 455.5 & 506.8 & 218.2 & 152.9 & Joint Panel Shear \\
\hline \multicolumn{11}{|c|}{ For CHS Diameter variation, $d_{c}$} \\
\hline 273.0 & 422.3 & 809.1 & 118.7 & 258.9 & 126.7 & 364.4 & 405.4 & 171.5 & 118.7 & Joint Panel Shear \\
\hline 323.9 & 508.3 & 685.6 & 116.6 & 258.9 & 180.4 & 364.4 & 405.4 & 173.4 & 116.6 & Joint Panel Shear \\
\hline 355.6 & 561.8 & 639.0 & 118.3 & 258.9 & 218.7 & 364.4 & 405.4 & 174.6 & 118.3 & Joint Panel Shear \\
\hline 375.0 & 594.5 & 616.8 & 119.9 & 258.9 & 243.9 & 364.4 & 405.4 & 175.3 & 119.9 & Joint Panel Shear \\
\hline 406.4 & 647.4 & 587.9 & 123.4 & 258.9 & 287.7 & 364.4 & 405.4 & 176.5 & 123.4 & Joint Panel Shear \\
\hline \multicolumn{11}{|c|}{ For Flange Plate thickness variation, $t_{f}$} \\
\hline 12.0 & 561.8 & 639.0 & 118.3 & 258.9 & 218.7 & 364.4 & 405.4 & 174.6 & 118.3 & Joint Panel Shear \\
\hline 14.0 & 561.8 & 639.0 & 119.0 & 258.9 & 218.9 & 312.4 & 392.0 & 168.8 & 119.0 & Joint Panel Shear \\
\hline 16.0 & 561.8 & 639.0 & 119.7 & 258.9 & 219.1 & 273.3 & 381.9 & 164.5 & 119.7 & Joint Panel Shear \\
\hline 18.0 & 561.8 & 639.0 & 120.4 & 258.9 & 219.3 & 243.0 & 374.1 & 161.1 & 120.4 & Joint Panel Shear \\
\hline 20.0 & 561.8 & 639.0 & 121.1 & 258.9 & 219.6 & 218.7 & 368.0 & 158.5 & 121.1 & Joint Panel Shear \\
\hline \multicolumn{11}{|c|}{ For Web Plate thickness variation, $t_{w}$ with Low Flange Thickness (LFT) $\left(t_{f}=12 \mathrm{~mm}\right)$} \\
\hline 10.0 & 561.8 & 639.0 & 118.3 & 258.9 & 218.7 & 364.4 & 405.4 & 174.6 & 118.3 & Joint Panel Shear \\
\hline 12.0 & 673.4 & 639.0 & 129.3 & 258.9 & 218.7 & 364.4 & 423.5 & 182.4 & 129.3 & Joint Panel Shear \\
\hline 14.0 & 784.6 & 639.0 & 140.2 & 258.9 & 218.7 & 364.4 & 441.5 & 190.1 & 140.2 & Joint Panel Shear \\
\hline 16.0 & 895.5 & 639.0 & 151.2 & 258.9 & 218.7 & 364.4 & 459.6 & 197.9 & 151.2 & Joint Panel Shear \\
\hline 18.0 & 1005.9 & 639.0 & 162.0 & 258.9 & 218.7 & 364.4 & 477.6 & 205.7 & 162.0 & Joint Panel Shear \\
\hline \multicolumn{11}{|c|}{ For Web Plate thickness variation, $t_{w}$ with High Flange Thickness (HFT) $\left(t_{f}=20 \mathrm{~mm}\right)$} \\
\hline 10.0 & 561.8 & 639.0 & 121.1 & 258.9 & 219.6 & 218.7 & 368.0 & 158.5 & 121.1 & Joint Panel Shear \\
\hline 12.0 & 673.4 & 639.0 & 132.4 & 258.9 & 219.6 & 218.7 & 378.4 & 163.0 & 132.4 & Joint Panel Shear \\
\hline 14.0 & 784.6 & 639.0 & 143.6 & 258.9 & 219.6 & 218.7 & 388.8 & 167.4 & 143.6 & Joint Panel Shear \\
\hline 16.0 & 895.5 & 639.0 & 154.8 & 258.9 & 219.6 & 218.7 & 399.3 & 171.9 & 154.8 & Joint Panel Shear \\
\hline 18.0 & 1005.9 & 639.0 & 165.9 & 258.9 & 219.6 & 218.7 & 409.7 & 176.4 & 165.9 & Joint Panel Shear \\
\hline \multicolumn{11}{|c|}{ For varying Moment-to-shear (M/V) ratio by varying beam length $\left(L_{b}\right)$ with LFT $\left(t_{f}=12 \mathrm{~mm}\right)$} \\
\hline 2500.0 & 561.8 & 639.0 & 261.3 & 631.0 & 437.3 & 364.4 & 405.4 & 378.1 & 261.3 & Joint Panel Shear \\
\hline 3400.0 & 561.8 & 639.0 & 182.0 & 415.9 & 321.6 & 364.4 & 405.4 & 266.4 & 182.0 & Joint Panel Shear \\
\hline 5000.0 & 561.8 & 639.0 & 118.3 & 258.9 & 218.7 & 364.4 & 405.4 & 174.6 & 118.3 & Joint Panel Shear \\
\hline 6600.0 & 561.8 & 639.0 & 87.6 & 188.0 & 165.7 & 364.4 & 405.4 & 129.9 & 87.6 & Joint Panel Shear \\
\hline 7500.0 & 561.8 & 639.0 & 76.5 & 162.9 & 145.8 & 364.4 & 405.4 & 113.5 & 76.5 & Joint Panel Shear \\
\hline \multicolumn{11}{|c|}{ For Material variation $\left(f_{y p} \& f_{y c}\right)$} \\
\hline $275.0 \& 275.0$ & 367.8 & 466.1 & 82.2 & 169.5 & 159.5 & 265.8 & 295.7 & 127.4 & 82.2 & Joint Panel Shear \\
\hline $355.0 \& 355.0$ & 474.8 & 601.7 & 106.0 & 218.9 & 205.9 & 343.2 & 381.8 & 164.4 & 106.0 & Joint Panel Shear \\
\hline $440.0 \& 440.0$ & 588.5 & 745.8 & 131.4 & 271.3 & 255.2 & 425.3 & 473.2 & 203.8 & 131.4 & Joint Panel Shear \\
\hline $420.0 \& 377.0$ & 561.8 & 639.0 & 118.3 & 258.9 & 218.7 & 364.4 & 405.4 & 174.6 & 118.3 & Joint Panel Shear \\
\hline $355.0 \& 440.0$ & 474.8 & 745.8 & 120.2 & 218.9 & 255.2 & 425.3 & 473.2 & 203.8 & 120.2 & Joint Panel Shear \\
\hline $440.0 \& 355.0$ & 588.5 & 601.7 & 117.2 & 271.3 & 205.9 & 343.2 & 381.8 & 164.4 & 117.2 & Joint Panel Shear \\
\hline
\end{tabular}

2 Reference configuration chosen for parametric studies: two through flange plates with $b_{f}=180 \mathrm{~mm}, t_{f}=12$ and $20 \mathrm{~mm}$; through web plate with $h_{w}=320 \mathrm{~mm}, t_{w}=10 \mathrm{~mm}$; CHS column with $d_{c}=355.6 \mathrm{~mm}, t_{c}=10 \mathrm{~mm}, L_{c}=2340 \mathrm{~mm}$; overall beam length $L_{b}=5000 \mathrm{~mm}$, material yield strength for the plates and beams, $f_{y p}=420 \mathrm{Mpa}$, and CHS columns, $f_{y c}=377 \mathrm{Mpa}$, and IPE 400 as the "main" I-beam sections. 


\section{MODELLING APPROACH AND EXPERIMENTAL VALIDATION OF THE NUMERICAL MODELS}

This section presents the modelling techniques adopted to build the numerical prototypes, which are used to characterize and design the proposed LASTEICON configuration through detailed parametric studies. These numerical prototypes were modelled in the finite element software DIANA 10.2 [37] and were validated with respect to relevant experimental investigations obtained in the frame of project LASTEICON.

\section{Modelling assumptions and Finite Element (FE) models}

The CHS column, through plates and the main beams were modelled using 3D geometries and were later meshed with solid elements such as CHX60, CTP45, and CTE30. Detailed information regarding the foretold elements can be found in the in-built element library [38] of DIANA 10.2. The element meshing for the CHS column and through members were kept approximately uniform for all models in order to maintain consistency and have a reliable comparison study with the parametric variations. Slots were considered in the CHS column surface to allocate the through plates and allow for the reduction in CHS stiffness. To avoid any secondary connection failure and rather focus on the Plates-to-CHS "passing-through" zone, the slots in these numerical models were defined assuming a zero tolerance, thus perfectly connecting the CHS column with the through plates with a perfectly welded connection. To avoid complicated numerical models and convergence issues and save more computation time, bolts and welds were not modelled explicitly and the members were connected through common nodes. Fig. 9 shows some examples for the numerical models and their meshing.

(a)

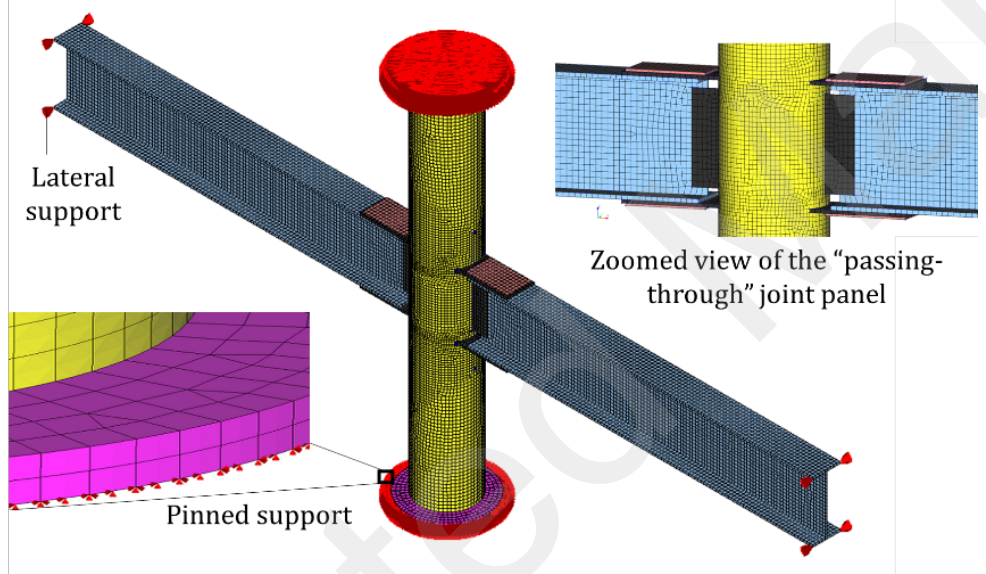

(b)

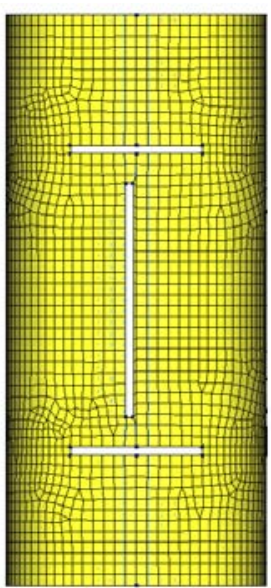

Fig. 9. Examples of numerical model meshed in DIANA 10.2, (a) isometric view of the "passing-through" connection configuration, (b) slots on the CHS column.

Two different load cases, a gravitational loading scenario, LC1 (Fig. 4a); and an opposite bending loading, LC2 (Fig. 4b); were considered for the numerical parametric studies. Pinned boundary conditions were used both at the top and bottom of the CHS column. The nominal stress-strain relationships obtained from the experimental prototypes were transformed into real stress-strain relationships. These real stress-strain curves were used to introduce nonlinear plasticity in the numerical models (Fig. 12). However, the real stressstrain data obtained from the tests were further approximated to reduce computational time and avoid heavier post processing files. Although a S355 material was chosen for all members, four different material yield strength were obtained for each member such as: for the through flange and web plates, main beams and the CHS column (see Fig. 12). The material yield strength for the through flange plates (FP in Fig. 12), $f_{y F P}$, for the through web plates (WP in Fig. 12), $f_{y W P}$, for the main I-beam, $f_{y b}$ and for the CHS column, $f_{y c}$, was found to be $420 \mathrm{MPa}$, 300MPa, $355 \mathrm{MPa}$ and $377 \mathrm{MPa}$ respectively. However, using four different material properties in one numerical model produced several convergence issues and were therefore modified in the parametric studies to avoid unnecessary complications. 


\section{Experimental Validation of the Numerical FE Models}

A preliminary experimental campaign was carried over by INSA, Rennes [39] to validate the numerical models for both load cases. Two additional solid circular plates, with $30 \mathrm{~mm}$ thickness and $520 \mathrm{~mm}$ diameter, were connected to each extremity of the CHS column (see Fig. 10) and was pinned by rollers following the boundary conditions shown in Fig. 4. The bottom roller was fixed by cleats bolted to the slab, whereas the upper one was fixed by cleats bolted to a HEB 400 beam. This beam was further bolted to two HEA 300 columns and fixed by four lateral bracings composed of HEA 200, as shown in Fig. 10. Lateral-torsional bracings were placed (see Fig. 10) to limit the lateral torsional buckling of the beam. Additional stiffener plates were welded to the beam flanges at the connection zones to limit any local flexural buckling. All of these additional members used, such as the solid circular plates used to fix the rollers as well as the aforementioned stiffener plates to limit local buckling, were also considered in the numerical models to have an identical replica of the experimental specimens and thus provide an appropriate validation (Fig. 9). Two load-jacks of $1500 \mathrm{KN}$ capacity, was applied at each extremity of the beam at a distance of $2500 \mathrm{~mm}$ from the axis of the CHS column for LC1. This distance was reduced to $1700 \mathrm{~mm}$ for LC2 to allow for a larger rotation of the node at failure. The loadings were applied in three steps: (i) Applications of $50 \%$ of the design resistance evaluated with nominal mechanical characteristics and unloading, (ii) Application of $100 \%$ of the design resistance and unloading, and (iii) Loading until failure of the joint or the beam. Two inclinometers, $I_{\mathrm{d}}$ and $I_{\mathrm{g}}$, were placed at the end of the connection and LVDTs $\left(V_{1 \mathrm{~g}}, V_{1 \mathrm{~d}} \ldots\right)$ were placed at relevant positions to measure the vertical and horizontal displacements [39].

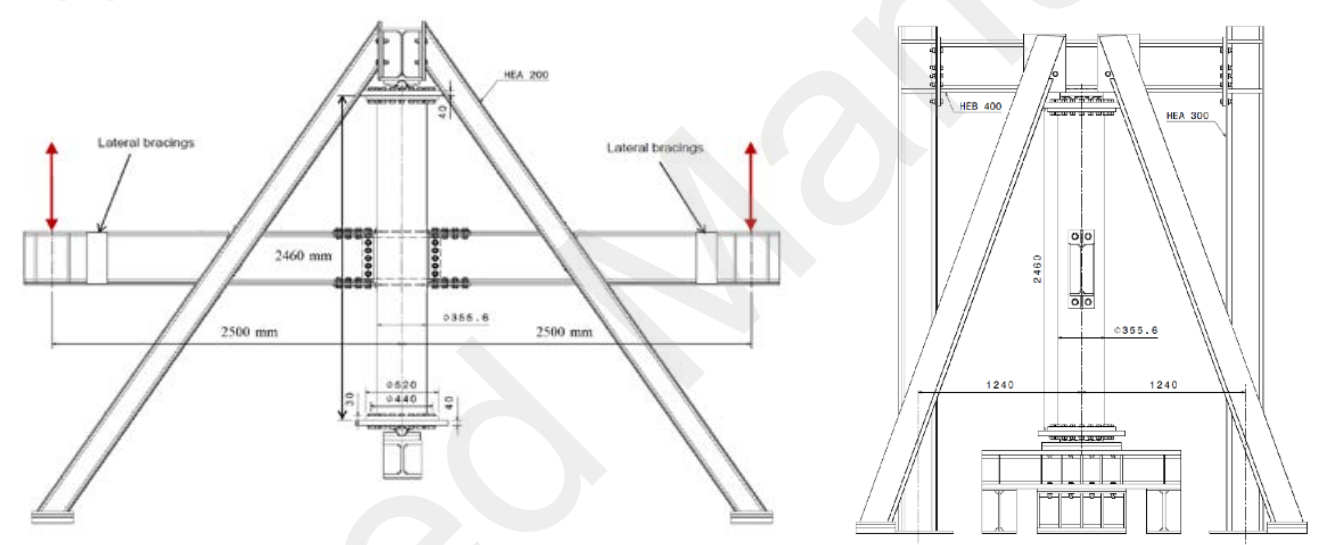

Fig. 10. Description of the Test set-up used in INSA, Rennes [39]

Three specific connection configurations were investigated in the preliminary experimental stage: two different LASTEICON connection configurations (one for each load case, LC1 and LC2) and one conventional Plates-to-CHS connection configuration under LC1 without any "passing-through" mechanism (Fig. 11). The plates were directly welded to the CHS column surface for the third test. Geometrical specifications regarding the through plates, main beam and CHS column specimens are provided in Table 3. IPE400 sections were adopted as the main beams in all cases. Results obtained from these three experiments were thus compared with the numerical results through force-displacement curves and detected failure modes. The vertical loads were applied at both the extremities of the "main" beams and were increased simultaneously step-by-step. However, due to similar results, the force-displacement curves (i.e. vertical load and beam deflection values at the loading point) obtained from the numerical and experimental results (Fig. 13) were compared for only one extremity of the "main" beam. To have an appropriate comparison between the numerical and experimental models in terms of the elastic stiffness, the experimental force-displacement curve under LC1 was further refined by removing the relative displacement occurring due to bolts sliding which could be calculated from the relevant LVDTs [39]. To identify "failure" in the numerical FE-models, the accumulated plastic strains were compared to a limit value which was calibrated with respect to the test results. For each tested specimen and its corresponding FE-model, the location and the values of the accumulated plastic strains were compared at the deformation stage of the tested specimens corresponding to the first visually detected failure (i.e. flange 
plate buckling in LASTEICON_LC1, CHS wall tearing in LASTEICON_LC2 and CHS wall crushing in Conventional_LC1).

Table 3: Specimens tested in the Preliminary Experimental Campaign

\begin{tabular}{lll|c|ccccc|cc}
\hline $\begin{array}{c}\text { Configuration } \\
\text { Type }\end{array}$ & $\begin{array}{l}\text { Loading } \\
\text { Scenario }\end{array}$ & Specimen Name & $\begin{array}{c}L_{b} \\
(\mathrm{~mm})\end{array}$ & $\begin{array}{c}h \\
(\mathrm{~mm})\end{array}$ & $\begin{array}{c}b \\
(\mathrm{~mm})\end{array}$ & $\begin{array}{c}h_{w} \\
(\mathrm{~mm})\end{array}$ & $\begin{array}{c}t_{w} \\
(\mathrm{~mm})\end{array}$ & $\begin{array}{c}t_{f} \\
(\mathrm{~mm})\end{array}$ & $\begin{array}{c}d_{c} \\
(\mathrm{~mm})\end{array}$ & $\begin{array}{c}t_{c} \\
(\mathrm{~mm})\end{array}$ \\
\hline LASTEICON & LC1 & LASTEICON_LC1 & 5000.0 & 424 & 180 & 320 & 10.0 & 12.0 & 355.6 & 10.0 \\
LASTEICON & LC2 & LASTEICON_LC2 & 3400.0 & 424 & 180 & 320 & 10.0 & 12.0 & 355.6 & 12.5 \\
Conventional & LC1 & Conventional_LC1 & 5000.0 & 424 & 180 & 320 & 08.0 & 10.0 & 355.6 & 08.8 \\
\hline
\end{tabular}

(a)

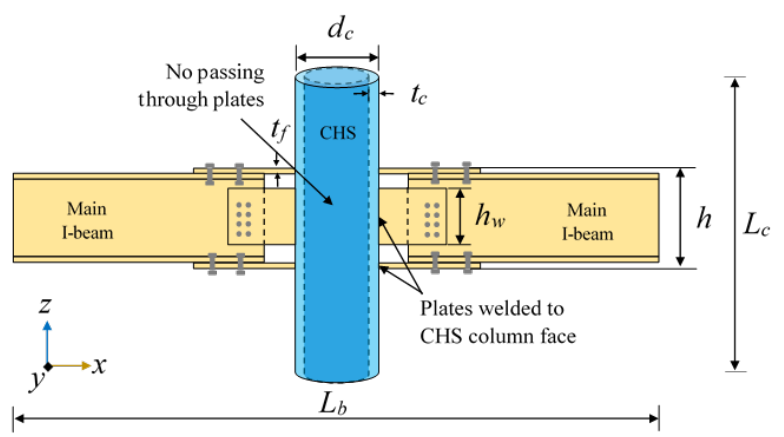

(b)

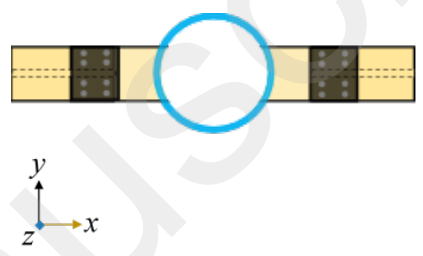

Fig. 11. Schematic diagram of a conventional Plates-to-CHS connection (a) frontal view and (b) top view

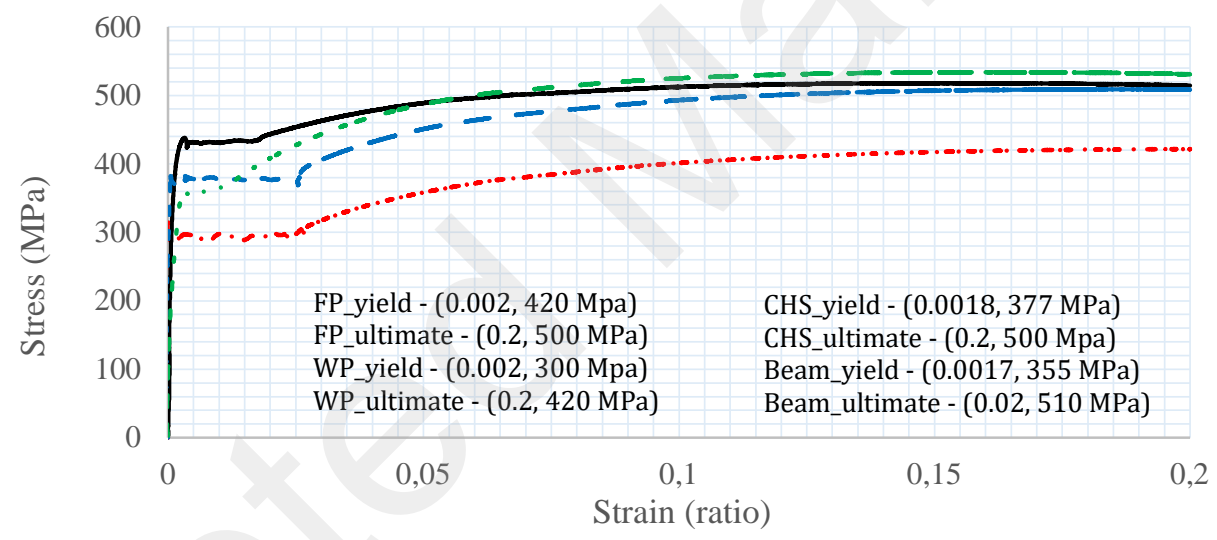

—FP_Exp_Data - - - . WP_Exp_Data ……… CHS_Exp_Data - - - Beam_Exp_Data

Fig. 12. Real stress-strain relationship obtained from the experimental tests 


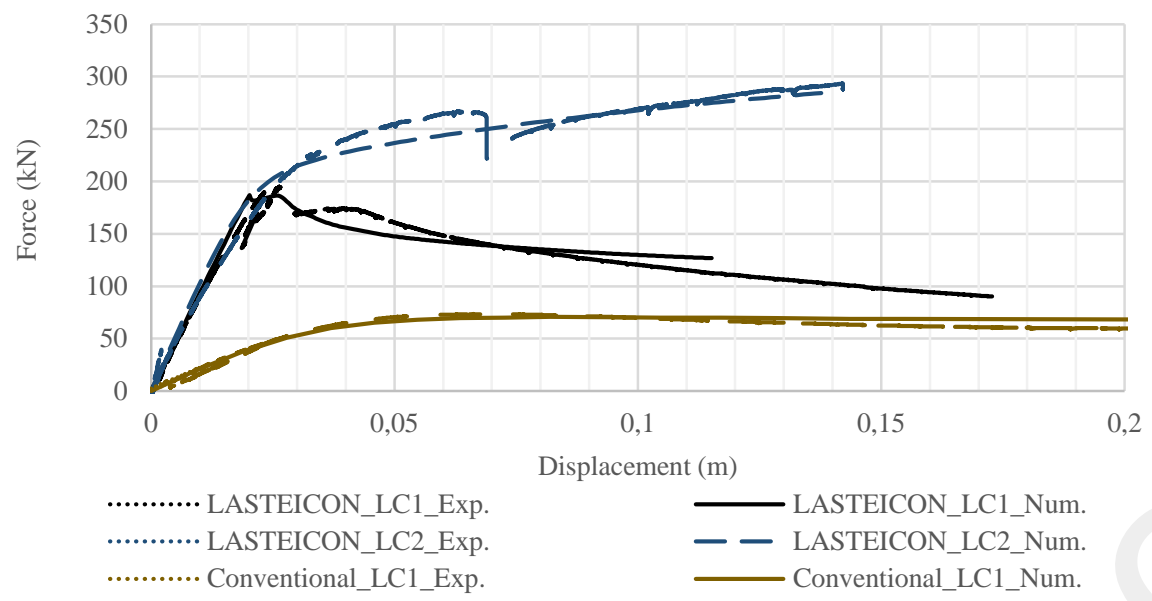

Fig. 13. Comparison of force-displacement curves between numerical and experimental results

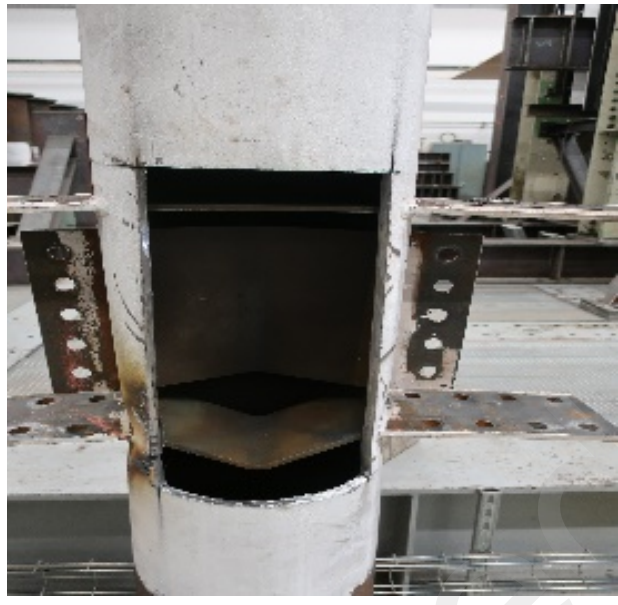

(a)

Fig. 14. LASTEICON_LC1 Failure: (a) flange and web plate buckling inside the CHS column observed from the experiments, (b) flange and web plate buckling inside the CHS column and, (c) Von mises equivalent plastic strains obtained from the numerical model

(a)

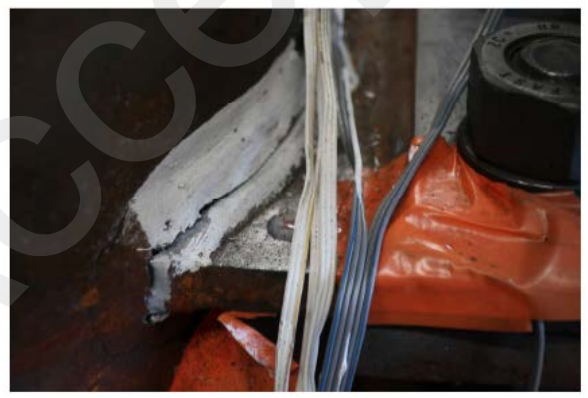

(b)

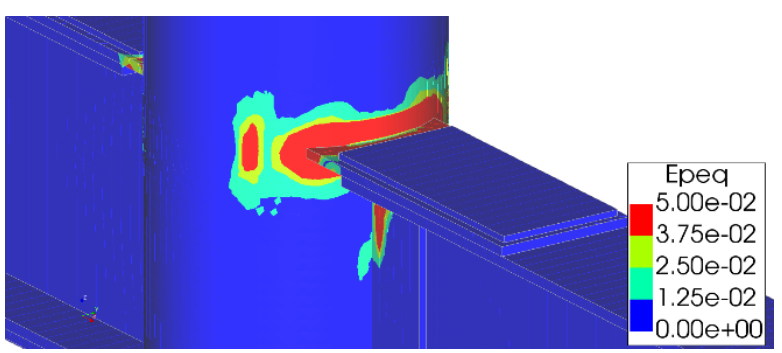

Fig. 15. LASTEICON_LC2 Failure: (a) CHS column wall tearing at the flange plate-to-column connection zone observed from the experiments and (b) Von mises equivalent plastic strains concentrated at the CHS-to-flange connection zone obtained from the numerical model 
(a)

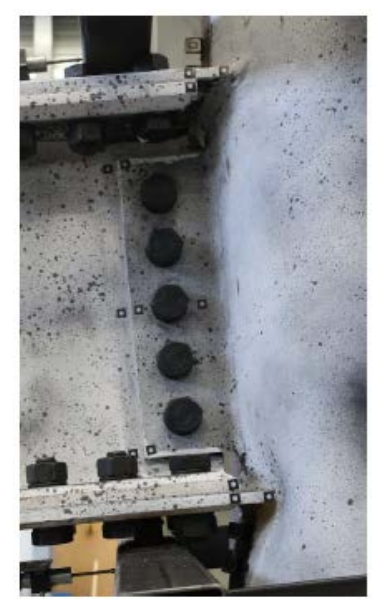

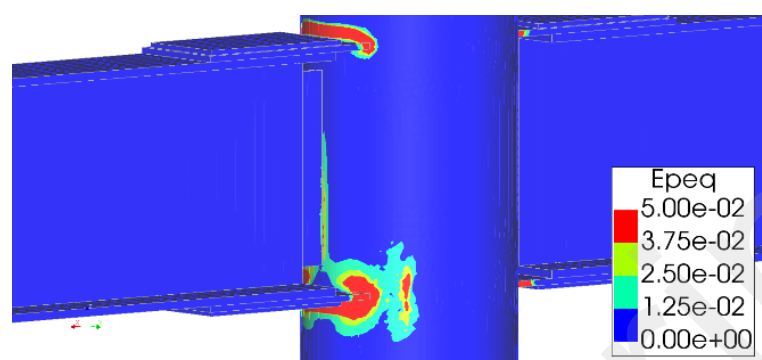

(b)

Fig. 16. Conventional_LC1 Failure: (a) CHS chord crushing observed from experiments and (b) Von mises equivalent plastic strains obtained from the numerical model

A good agreement was found between the experimental (_Exp.) and numerical (_Num.) results in terms of initial stiffness and ultimate resistance of the LASTEICON as well as the conventional joints as shown by the force displacement curves plotted in Fig. 13. Furthermore, the failure modes obtained from the numerical models also agreed with the experimental prototypes as shown in Fig. 14, 15 and 16 respectively for LASTEICON_LC1, LASTEICON_LC2 and Conventional_LC1. Failure in LASTEICON_LC1 occurred due to the through flange plate buckling (Fig. 14a) inside the CHS column at a similar load level $(\approx 190 \mathrm{kN})$ for both the numerical and the experimental prototype. This is clearly visible from the concentrated deformation (Fig. 14b) and plastic strains (Fig. 14c) obtained at the relevant zones of the flange and web plates inside the CHS column. Failure in the LASTEICON_LC2 specimen occurred due to a tearing of the CHS column surface at the CHS-to-through flange plate connection zone (Fig. 15a). Although such a brittle failure could not be predicted by the numerical prototype, a similar trend was observed in terms of strains concentration (Fig. 15b) in the CHS-to-through flange plate connection zone. Failure in both the numerical and experimental LASTEICON_LC2 was also recorded to occur at a similar load level $(\approx 280 \mathrm{kN})$. A sudden decrease was noticed in the experimental force-displacement curve for LASTEICON_LC2. It occurred due to weld tearing in the through plates-to-CHS connection zone. However, as this research study solely focuses on the "passing-through" zone, the welds were not explicitly modelled in the numerical prototypes and is based on the assumption that the plates are perfectly welded to the CHS, as mentioned earlier in this section. As a consequence, the numerical prototypes are unable to predict any weld tearing and hence showed a smoother force-displacement behavior. The experimental observations also showed that the initial weld tearing phenomenon did not have much impact on the ultimate behavior of the "passing-through" joint strength and could therefore be disregarded for the assessment of the joint zone. This phenomenon however occurred due to a shear failure of the through web plate and transverse tensile failure of the CHS column wall. It is explained in section 4.3 and 4.4 with more details. Failure mode in the conventional joint configuration under LC1, also agreed with each other as high plastic strains developed on the CHS column wall at the Plate-to-CHS welded connection zones due to transverse compressive stresses at a load level of approximately $70 \mathrm{kN}$ (Fig. 16).

\section{PARAMETRIC STUDY ON THE LASTEICON CONFIGURATION BASED ON NONLINEAR STATIC ANALYSIS}

A detailed parametric study was carried over to examine and validate the analytical design guidelines. Six major parameters were principally identified to have a significant effect on the ultimate joint strength (as illustrated in Fig. 17): (1) CHS column thickness $\left(t_{c}\right)$ (2) CHS column diameter $\left(d_{c}\right)$ (3) Through flange plate thickness $\left(t_{f}\right)(4)$ Through web plate thickness $\left(t_{w}\right)(5)$ Material properties for both CHS and through plates $\left(f_{y c}\right.$ and $f_{y p}$ ) (6) Moment-to-shear (M/V) ratio. A reference configuration was chosen throughout the parametric variations, which constituted of two IPE400 sections as the main beams connected at each side of the CHS 
column connection via two $180 \mathrm{~mm}$ wide and $12 \mathrm{~mm}$ thick through flange plates and a $320 \mathrm{~mm}$ deep and $10 \mathrm{~mm}$ thick through web plate. The CHS column had a diameter $\left(d_{c}\right)$ of $355.6 \mathrm{~mm}$ and a thickness $\left(t_{c}\right)$ of $10 \mathrm{~mm}$ with an overall beam length $\left(L_{b}\right)$ of $5000 \mathrm{~mm}$. As mentioned earlier, to avoid heavy complicated models and numerous convergence issues, only two material models were considered for the parametric studies. While the CHS column was modelled with its material model $\left(f_{y c}=377 M p a\right)$ obtained from the experiments, the through flange plates, web plates as well as the main beams were modelled with the material properties obtained for the through plates $\left(f_{y F P}=420 M p a\right)$ shown in Fig. 12. The material used for both the through flange and web plates is denoted as $f_{y p}$ in this section. Configurations were studied under both loading conditions, LC1 (Fig. 4a) and LC2 (Fig. 4b), for each parametric variation and the corresponding joint behaviours are discussed below. The loads were applied to the relevant extremities and were incremented to obtain the full force-displacement curves. The monitored displacement corresponds to the loaded point. Investigated parametric variations are listed in Table 1 and 2 in blue columns with their ultimate joint strengths under symmetric and opposite loading scenario. All analytical design calculations were thus compared with the numerical results in terms of resistance and failure mode. The dotted horizontal lines in the forcedisplacement curves under LC1 and LC2 corresponds to the $V_{b u, s y m}$ and $V_{b u, o p p}$ values listed in Table 1 and 2 respectively.

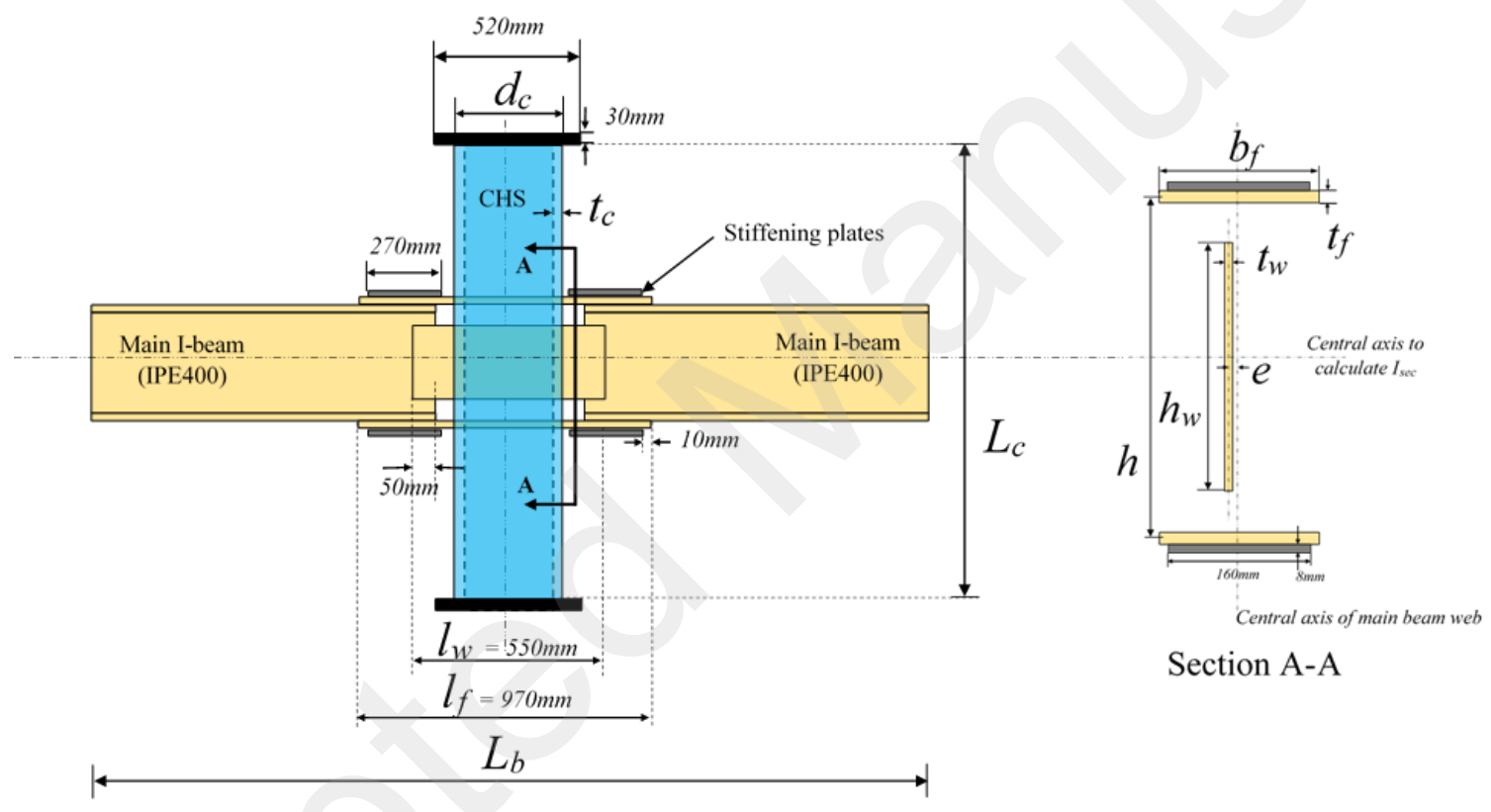

Fig. 17. Parametric dimensions for the LASTEICON configuration highlighting the unchanged dimensions used throughout the parametric study

\subsection{CHS column thickness $\left(t_{c}\right)$}

The CHS column thickness was varied from a smallest of $4 \mathrm{~mm}$ to a largest $12.5 \mathrm{~mm}$ as listed in Table 1 and 2 to understand all possible failure sequences occurring due to failure in the CHS column under LC1 and LC2. Although $t_{c}$ had a significant effect under LC2 in terms of strength, it produced a comparatively smaller difference in the force-displacement curves under LC1. Force-displacement curves for LC1 and LC2 for CHS thickness variation are shown in Fig. 18 and 19 respectively. 


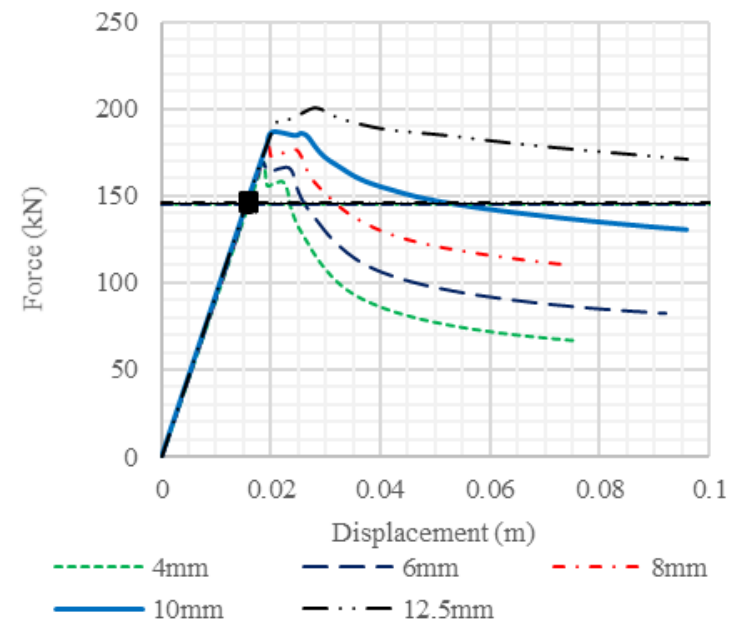

Fig. 18. Vertical force-displacement curve comparisons for varying CHS column thickness under LC1

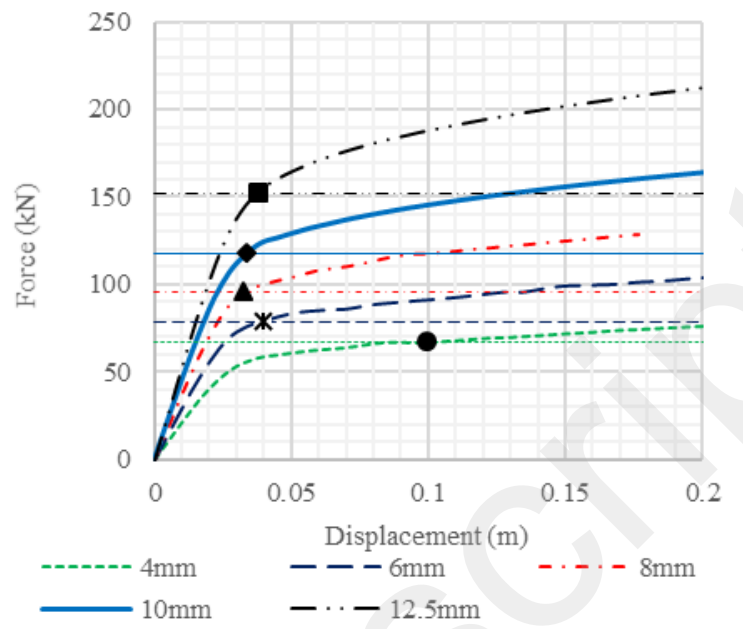

Fig. 19. Vertical force-displacement curve comparisons for varying CHS column thickness under

In the numerical parametric study, failure was assumed to be reached when the plastic strain reached the limiting value of the equivalent plastic strain obtained from the experiments failing in a similar way (strain limit generally around 5\%). In all cases under LC1, the numerical models agreed with the design calculations as a through flange plate buckling under compression was observed for all prototypes (see Table 1). The first peak obtained from the force-displacement curves represents the through flange plate buckling (Fig. 20a) whereas the second peak denotes the buckling of the through web plate (Fig. 20b) followed by a compressive crushing of the CHS wall. Although the ultimate failure of the numerical models under LC1 was obtained due to a compressive crushing of the CHS wall, the first failure point i.e. the through flange plate buckling in compression was defined to be the critical failure to develop the design procedure. Corresponding analytical values were thus compared in Fig. 18. As the failure was governed by the through flange plates, which were kept constant throughout this parametric investigation, similar stiffness was obtained from the forcedisplacement curves. However, small differences were noticed in terms of strength and also the corresponding safety margin between the analytical and numerical values. Although a fixed-fixed boundary condition was assumed to calculate the effective buckling length $(a)$ of the through plate under compression, and was taken as half of the actual length $\left(l_{f p}\right)$, it did not hold true for the Class 4 CHS sections $(4 \mathrm{~mm}$ and $6 \mathrm{~mm}$ thick CHS column). So, a linear eigenvalue buckling analysis was done and compared with the design assumptions. The $4 \mathrm{~mm}$ and $6 \mathrm{~mm}$ thick CHS column connection models were observed to offer a smaller degree of fixity than the other three models. As a consequence, the proposed design procedure strongly recommends against using Class 4 type CHS column sections in the "passing-through" LASTEICON connections. Furthermore, among the remaining numerical models $\left(t_{c}=8,10,12.5 \mathrm{~mm}\right)$, a thicker CHS column connection was clearly observed to provide a bit more resistance even after the through flange plate buckling (Fig. 18). This happened because a thicker CHS column can transfer larger forces to the through web plate after the compressive buckling of the through flange plate. This clarifies the post-flange-plate-buckling behaviour shown by the force-displacement curves in Fig. 18.

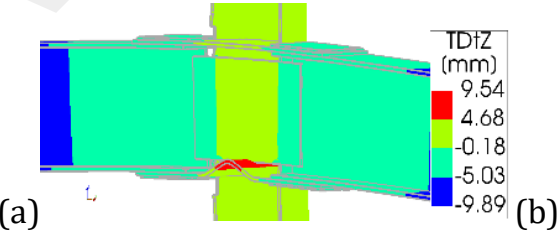

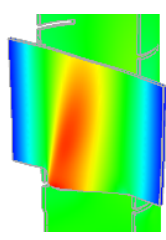

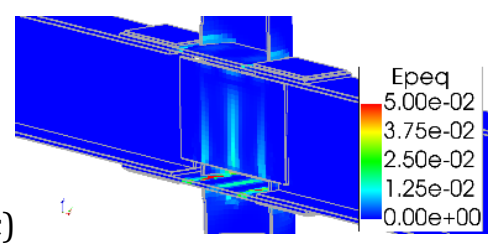


Fig. 20. (a) First occurrence of through flange plate buckling under compression, (b) through web plate buckling due to failure progression (c) Von mises equivalent strains obtained at the failure under LC1 for the connection with $10 \mathrm{~mm}$ thick CHS column

The CHS column thickness was observed to have a substantial effect in determining the joint strength under LC2. The $4 \mathrm{~mm}$ thick CHS column (Class 4 section) was observed to be vulnerable against punching shear. Although the punching shear resistance was obtained to be marginally higher than the actual joint strength according to the analytical calculations (Table 2), the joint indicated towards a punching shear failure rather than a joint panel failure, giving a prediction error of $2 \%$. Nevertheless, the remaining numerical prototypes with 6, 8, 10 and $12.5 \mathrm{~mm}$ CHS column thickness displayed a joint panel failure without any local distortions, thus supporting the analytical calculations. The ultimate joint strengths calculated as per Table 2 were further compared in Fig. 19 to highlight the safe agreement shared between the analytical and numerical solutions. The force transfer mechanism active under LC2 is further discussed in Section 4.4 for added relevance. As suggested by the analytical calculations in Section 2, slender CHS columns, specifically of Class 4 type, are susceptible to local buckling as well as punching shear failure. Although local buckling of the CHS columns was not observed in any cases, the slender column indicated towards a localised punching shear failure, thus highlighting the importance of the design checks. In this case, yielding occurred on the CHS column surface prior to substantial yielding in the through web plate (Fig. 21a). Ultimate stress concentration was observed on the CHS column surface above the flange connection zones (Fig. 22a) prior to development of failure stresses in the through web plate. On the other hand, yielding (Fig. 21b and Fig. 21c) and failure (Fig. 22b and Fig. 22c) stresses in other configurations, with a thicker CHS column, were clearly noticed to develop simultaneously in the through web plate (under shear) and the CHS column surface (under transverse tensile forces) and therefore the joint panel as a whole.

(a)

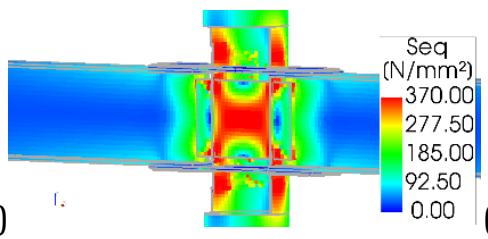

(b)

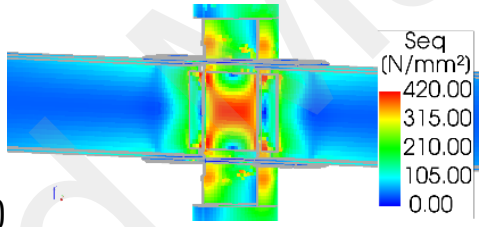

(c)

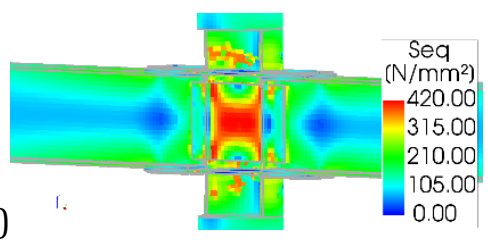

Fig. 21. Von mises equivalent stresses $\left(\mathrm{N} / \mathrm{mm}^{2}\right)$ at yield under LC2 for (a) connection with $4 \mathrm{~mm}$ thick CHS, (b) connection with $6 \mathrm{~mm}$ thick CHS, (c) connection with $12.5 \mathrm{~mm}$ thick CHS

(a)

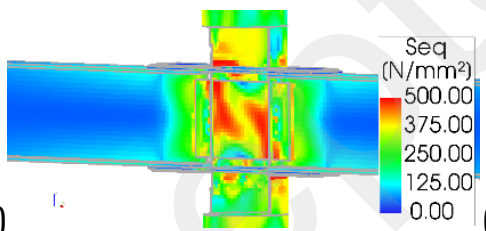

(b)

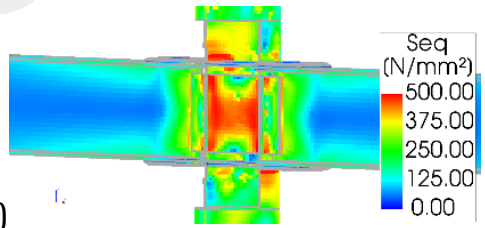

(c)

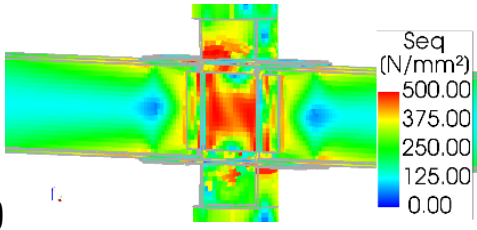

Fig. 22. Von mises equivalent stresses $\left(\mathrm{N} / \mathrm{mm}^{2}\right)$ at failure under LC2 for (a) connection with $4 \mathrm{~mm}$ thick CHS, (b) connection with $6 \mathrm{~mm}$ thick CHS, (c) connection with $12.5 \mathrm{~mm}$ thick CHS

\subsection{CHS column diameter $\left(d_{c}\right)$}

The CHS column diameter was varied from $273 \mathrm{~mm}$ to $457 \mathrm{~mm}$ (as listed in Table 1 and 2) which were chosen based on their availability in the steel construction industry. Force-displacement curves in Fig. 23 and 24 describes the effect of diameter variation under LC1 and LC2 respectively. 


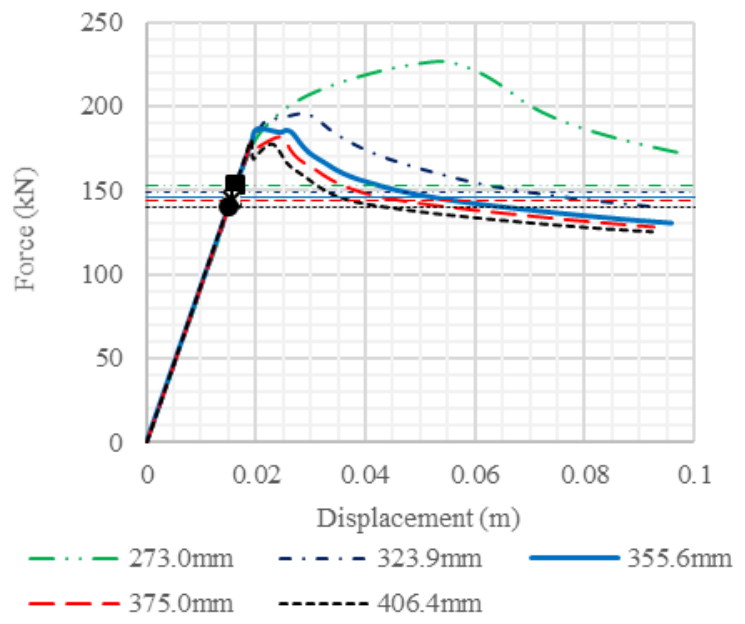

Fig. 23. Vertical force-displacement curve comparisons for varying CHS column diameter under LC1

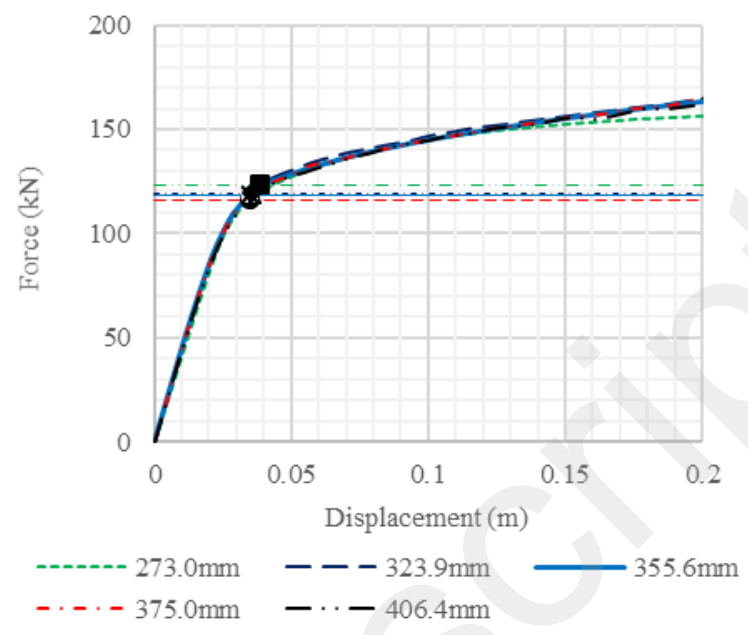

Fig. 24. Vertical force-displacement curve comparisons for varying CHS column diameter under

The CHS column diameter had a significant influence on the vertical force-displacement curves for LC1. By decreasing the diameter of the CHS column, the critical buckling length of the through flange plate decreased, hence increasing its buckling resistance under compressive stresses. Therefore, the LASTEICON configuration with the smallest diameter $\left(d_{c}=273 \mathrm{~mm}\right)$ offered the highest resistance and the configuration with the largest diameter $\left(d_{c}=406.4 \mathrm{~mm}\right)$ produced the lowest resistance (Fig. 23). A small yet significant inconsistency was however noticed as the configuration with $273 \mathrm{~mm}$ diameter offered a much larger safety margin compared to the other configurations. As shown in Fig. 23, the peak denoting the through flange (bottom) buckling under compression occurred quite late than expected and a plastic deformation before that was also noticed in the force-displacement curve. This happened due to the fact that the through flange under tension (top) reached its yield limit and offered flexural plasticity, thus delaying the buckling failure and increasing the joint resistance. The vertical load corresponding to the flexural resistance provided by the passing through section (assumed to be built by three individual through plates) was calculated to be $207 \mathrm{kN}$, which was significantly more than the vertical load corresponding to the buckling resistance. The Von mises equivalent stresses, strains as well as the through flange plate buckling is shown in Fig. 25a, 25b and 25c respectively, where the through flange plate under tension is noticed to reach high stresses due to bending while the other through plates (flange and web) buckle under compression. As a result, the predicted resistance obtained from the calculations proved to be quite conservative compared to the numerical result. However, as no pertinent solution was found to foresee this kind of behaviour, it was not discussed in this study and thus can be argued as a limitation of the proposed design approach. However, the other connection configurations behaved as expected. Vertical and transverse deformations in the passing through zone are shown in Fig. 26a and 26b respectively for the connection with $406.4 \mathrm{~mm}$ diameter to highlight the buckled flange and web plates with more clarity.

(a)

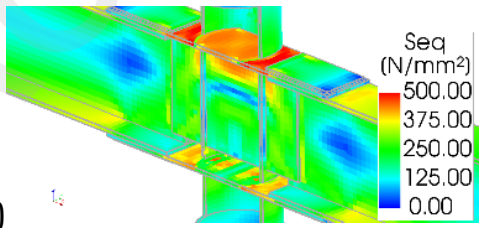

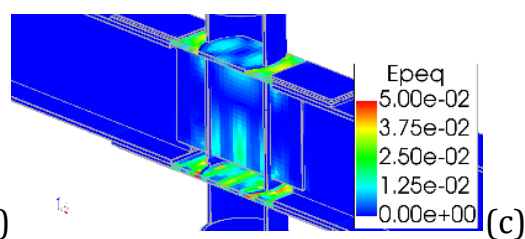

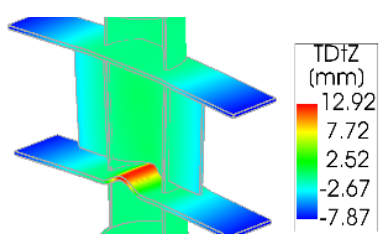


Fig. 25. (a) Von mises equivalent stresses $\left(\mathrm{N} / \mathrm{mm}^{2}\right)$ (b) Von mises equivalent strains, (b) through flange and web plate buckling in the deformed structure for the connection with $273 \mathrm{~mm}$ diameter CHS column at failure under LC1

(a)

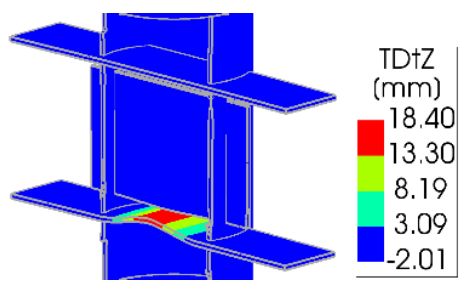

(b)

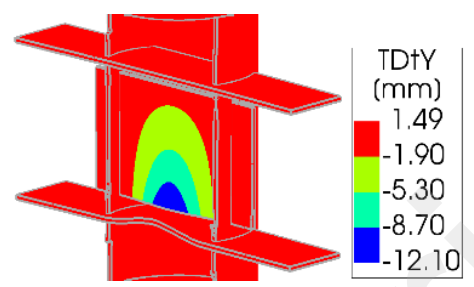

Fig. 26. Concentrated deformations (a) in the through flange plate, and (b) the through web plate for the connection with $406.4 \mathrm{~mm}$ diameter CHS column at failure under LC1

Contrary to the significant effects observed under LC1, the diameter variation failed to show any significant variation in the force-displacement curves under LC2. As shown in Fig. 24, the force-displacement curves were noticed to be almost similar along with the values predicted by the design approach. This, however, can be easily explained through the analytical values listed in Table 2. In this table, the column under "Resisting Components" shows us that, the configuration with the smallest diameter $\left(d_{c}=273.0 \mathrm{~mm}\right)$ should offer the smallest resistance via the through web plate but should produce the maximum resistance via the CHS column wall against transverse tension/compression and vice versa for the configuration with the largest diameter $\left(d_{c}\right.$ $=406 \mathrm{~mm}$ ). Therefore, it can be established that the similarity in the force-displacement curves were obtained due to the inverse relationship shared between the through web plate and the CHS column wall (in terms of resistance) rather than any misconception that the diameter does not play any major role under LC2. Successful arguments were observed in the FE models compared to the analytical calculations for all Classes of CHS. The through web plate and the CHS column surface failed simultaneously (a complete joint panel failure) for both, a Class 1 type CHS $\left(d_{c}=273.0 \mathrm{~mm}\right)$ and a Class 3 type CHS $\left(d_{c}=406.4 \mathrm{~mm}\right)$ column connection as shown in Fig. 27a and Fig. 27b respectively).

(a)

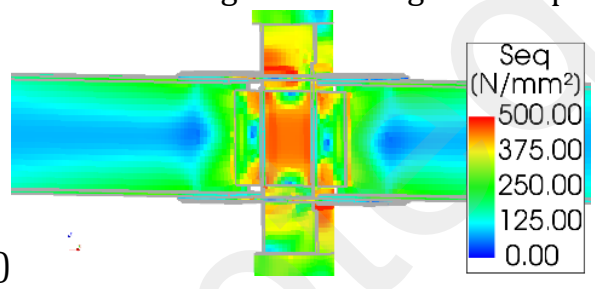

(b)

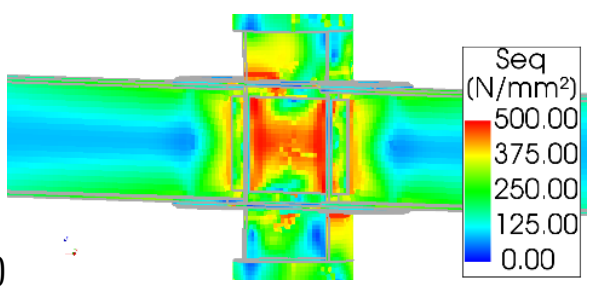

Fig. 27. Von mises equivalent stresses $\left(\mathrm{N} / \mathrm{mm}^{2}\right)$ in the through web plate for (a) connection with $273.0 \mathrm{~mm}$ diameter CHS, and (b) connection with 406.4mm diameter CHS column at failure under LC2

\subsection{Through flange plate thickness $\left(t_{f}\right)$}

The smallest through flange plate thickness considered in this study was $t_{f}=12 \mathrm{~mm}$ and was further increased to $20 \mathrm{~mm}$. Vertical force-displacement curves under LC1 and LC2 are plotted in Fig. 28 and 29 respectively. The force transfer mechanism for LC1 (discussed in Section 2.1) clearly assumed that the vertical loads applied at extremities of the main beams create a flexural action on the joint panel, developing compressive stresses on the bottom flange and tensile stresses on the top flange, therefore primarily effecting the through flange plates. So, the through flange plate thickness played a crucial role in determining the joint strength under LC1. The connection with $t_{f}=12 \mathrm{~mm}$ failed due to through flange plate buckling inside the CHS (Fig. 30a). $t_{f}$ was therefore increased by $2 \mathrm{~mm}$ at each step to analyse the strengthening of the joint panel and search for a suitable through flange plate thickness which could ensure a sufficient joint strength and avoid the local buckling phenomenon. 


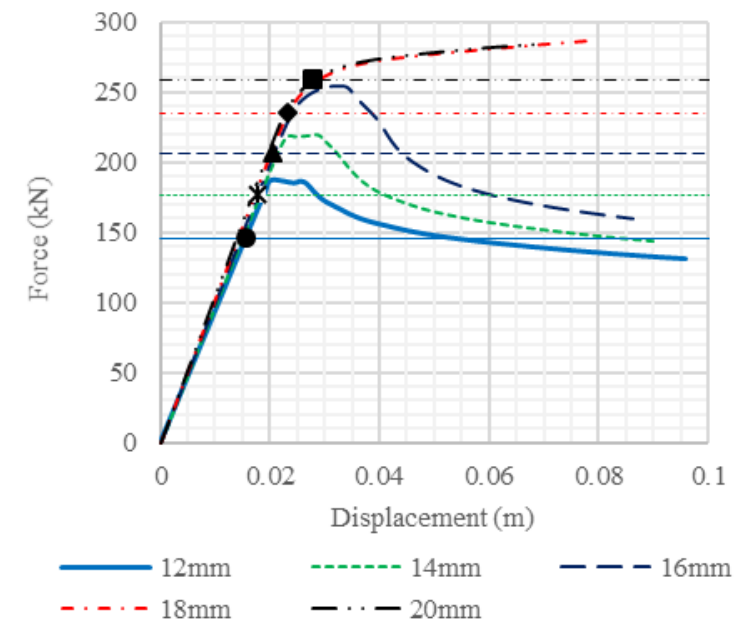

Fig. 28. Vertical force-displacement curve comparisons for varying through flange plates under LC1

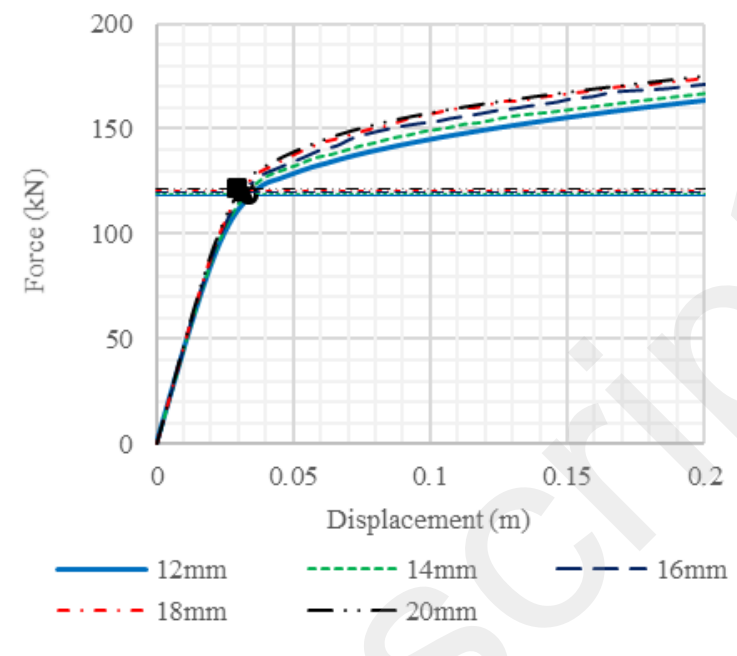

Fig. 29. Vertical force-displacement curve comparisons for varying through flange plates under

The numerical models showed that the connection with an $18 \mathrm{~mm}$ thick through flange plate was able to provide sufficient joint strength as the model failed due to flexural plasticity of the main beams at both sides (Fig. 30b). However, according to Table 1, the design approach predicted a failure due to through flange plate buckling inside the CHS column for this specific connection. As the $V_{b b}$ and $V_{b j, s y m}$ values were really close to each other for this particular case study, the design approach can be safely accepted as the relative prediction error was only $8 \%$. The $t_{f}$ was further increased to $20 \mathrm{~mm}$ to recheck the design values and this connection provided good agreement between the analytical and numerical results as in both cases the global prototype failed due to flexural plasticity in the main beams and avoided any through flange plate buckling (Fig. $30 \mathrm{c}$ ). Identical force-displacement curves were obtained for the configurations with $18 \mathrm{~mm}$ and $20 \mathrm{~mm}$ thick through flange plates because failure occurred due to plastic bending in the main beams, which were kept unchanged throughout this parametric variation. Thicker plates were also observed to increase the stiffness of the numerical models as expected. The ultimate joint strengths calculated as per Table 1 are further compared in Fig. 28 to highlight the agreement between the analytical and numerical results. The proposed design approach was also found to provide enough safety thanks to the material strain hardening as well as the considered safety factors.

Two types of failure were noticed under LC1: (1) through flange plate buckling under compression, and (2) flexure failure of the main I-beams with eventual plastic flange buckling near the connection zone (the furthest connection line shared between the through flange plate under compression and the main beam flange). A clear force transfer mechanism can therefore be identified under LC1: Failure type (1) occurs as a localised failure in the joint panel when the through flange plate fails to provide sufficient resistance to the joint panel, and therefore buckles inside the CHS column (first break in the force-displacement curves). After this, the forces are redistributed to the through web plate via the CHS column. When the web plate loses its capacity, it buckles under compressive stresses due to bending (second break in the force-displacement curves). Stresses are again redistributed along the CHS column wall and finally, the ultimate failure occurs due to the compressive crushing of the CHS column wall (end of the force-displacement curve). On the other hand, Failure type (2) occurs if the through flange plates are strong enough to provide the necessary resistance against buckling. In this case, the main beams eventually fail due to flexural plasticity just outside the main beam-to-through flange plate connection zone and consequently no breaks are observed in the curves thus providing a smooth force-displacement behaviour indicating a ductile connection. 
(a)

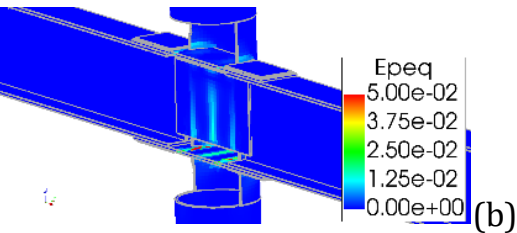

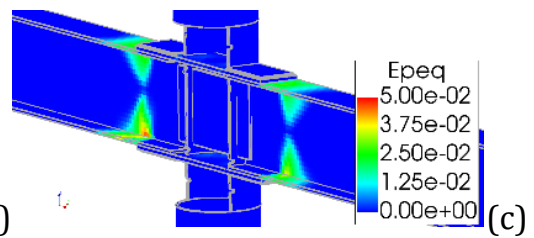

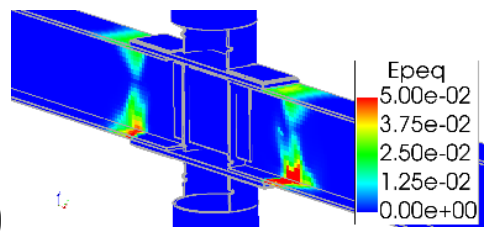

Fig. 30. Von mises equivalent strains showing (a) through flange plate buckling for $t_{f}=12 \mathrm{~mm}$, (b) plastic flange buckling due to flexural failure of main beams for $t_{f}=18 \mathrm{~mm}$, (c) plastic flange buckling due to flexural failure of main beams for $t_{f}=20 \mathrm{~mm}$, at failure under LC1

The force transfer mechanism assumed to determine the analytical joint strength under LC2 was also apparent from the numerical models. As already anticipated from the analytical calculations (Table 2), the through flange plate thickness had minimal contribution towards developing the joint strength under LC2 as shown in Fig. 29. However, a small yet visible increase in resistance was noticed, which occurred due to an increased lever arm distance $(h)$ between the top and bottom through flange plates. In all cases, yielding occurred simultaneously in both the through web plate as well as the CHS column surface.

(a)

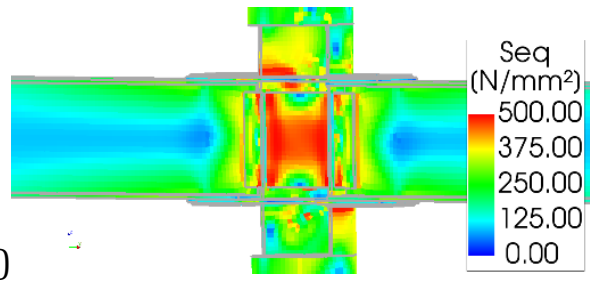

(b)

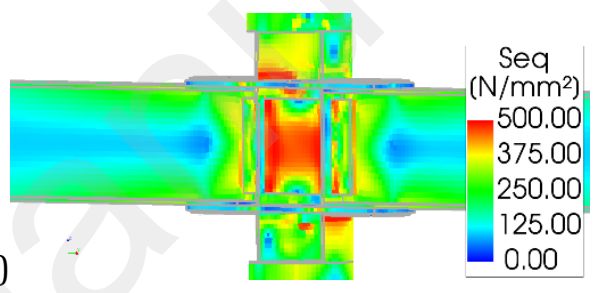

Fig. 31. Von mises equivalent stresses $\left(\mathrm{N} / \mathrm{mm}^{2}\right)$ for (a) connection with $t_{f}=12 \mathrm{~mm}$, (b) connection with $t_{f}=20 \mathrm{~mm}$, at failure under LC2

This again validates the previously proposed design approach as effective transmission of bending moments occurred through a combination of the shear resistance provided by the through web plate and the transverse tensile/compressive resistance of the CHS chord face. Maximum stresses at failure were observed at the faces of the CHS column at the flange connection zones (in tension) as well as the through web plate as shown in Fig. 31. These failure stresses at the connection zone of the CHS column clearly explains the tearing observed in the experimental prototype as shown in Fig. 15 and hence proves that it occurred due to an ultimate joint failure rather than any localized distortion of the CHS column wall.

\subsection{Through web plate thickness $\left(t_{w}\right)$}

The through web plate thickness, $t_{w}$, was varied from $10 \mathrm{~mm}$ to $18 \mathrm{~mm}$ for two different through flange plate thickness, $t_{f}$, as mentioned in Table 1 and 2 . This was done to check the consistency of the design approach and examine the predicted failure types obtained from the analytical calculations. The first through web plate thickness variation was done for the thinnest through flange plate $\left(t_{f}=12 \mathrm{~mm}\right)$ and the latter was done for the thickest one $\left(t_{f}=20 \mathrm{~mm}\right)$ considered in this study.

\subsubsection{Through web plate thickness ( $t_{w}$ ) for Low Flange Thickness (LFT)}

Under LC1, all configurations failed due to the through flange plate buckling (Table 1 and Fig. 32). As the through flange plate thickness was kept constant $(=12 \mathrm{~mm})$ and the web plate was assumed to carry zero moment, the analytically calculated joint strengths were found to be exactly equal for all configurations (Table 1). However, in reality, small moments are also carried by the web plate which somewhat contributes to the joint resistance. As a result, very small differences were noticed in the first peak obtained from the numerical force-displacement curves of all configurations (Fig. 32). Major differences were observed in the post-through flange plate-buckling phase (second peak) where the thickest web plate $(=18 \mathrm{~mm})$ provided approximately 
9\% more safety (analytical vs numerical) in terms of maximum resistance compared to the thinnest one (= $10 \mathrm{~mm}$ ). However, as mentioned in section 4.1, to keep a consistent safety margin, the through flange plate buckling was defined as the critical failure mode in the design approach rather than the ultimate resistance obtained from the combination of both the through flange and web plates. The stress distributions, forcedisplacement behaviour as well as the failure modes under LC2 also agreed with the corresponding analytical predictions as shown in Table 2. The force-displacement curves are plotted in Fig. 32 and 33 for the models under LC1 and LC2 respectively.

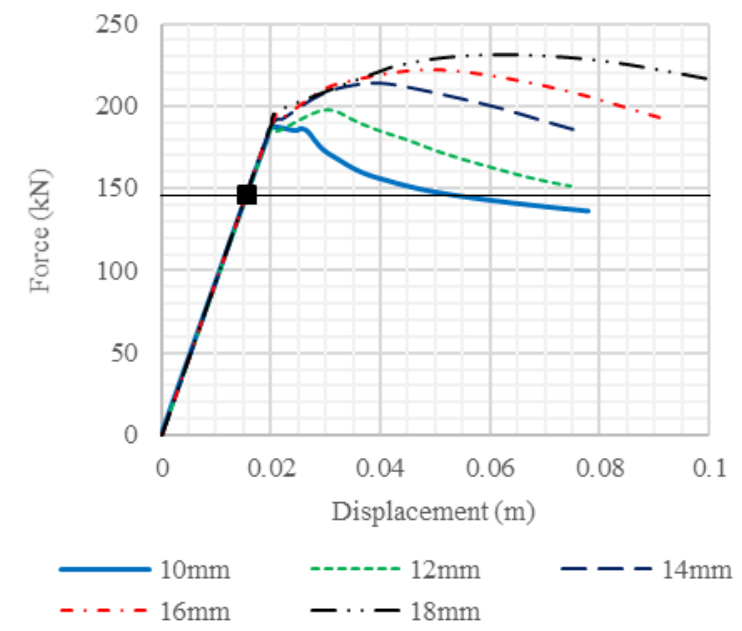

Fig. 32. Vertical force-displacement curve comparisons for varying through web plates for $t_{f}=$ $12 \mathrm{~mm}$ under $\mathrm{LC1}$

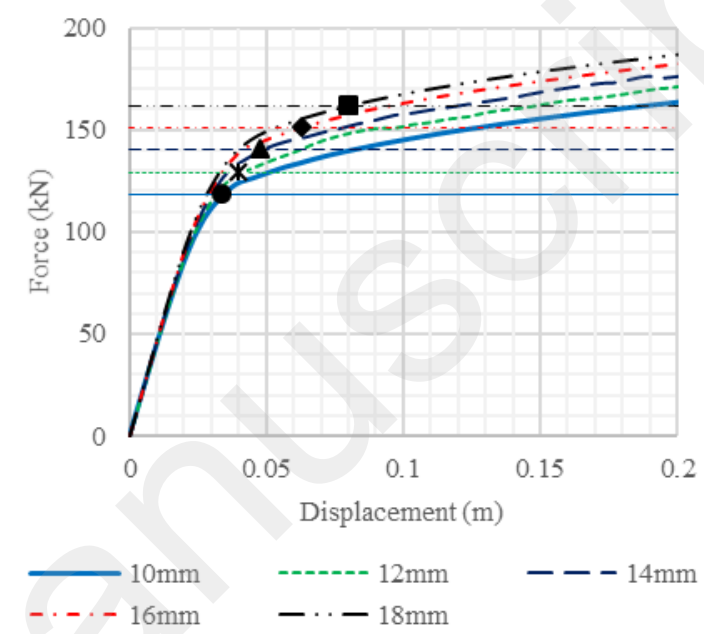

Fig. 33. Vertical force-displacement curve comparisons for varying through web plates for $t_{f}=$ $12 \mathrm{~mm} \quad$ under

The force transfer mechanism assumed in the design applications under LC2 was studied in a detailed manner via understanding the stress distributions on the through web plate as well as the CHS column surface. Although the CHS column wall did not provide any noticeable irregularities, the shear stress distribution along the vertical direction of the through web plate was observed to be non-uniform. This happened due to significant flexural stresses developing at the four corners of the through web plate therefore limiting a uniform shear stress distribution along its vertical axis. Multiple prototypes were modelled with elastic-perfectly-plastic S355 material properties to avoid any confusion occurring due to the material stain hardening characteristics to solely validate such an assumption. The shear stress distribution along the depth and length of the through web plate are illustrated in Fig. 34 and Fig. 35 respectively for one of these numerical prototypes. Due to a symmetrical stress distribution on either side of the central longitudinal axis, the shear stresses are plotted only for the top half of the through web plate. 


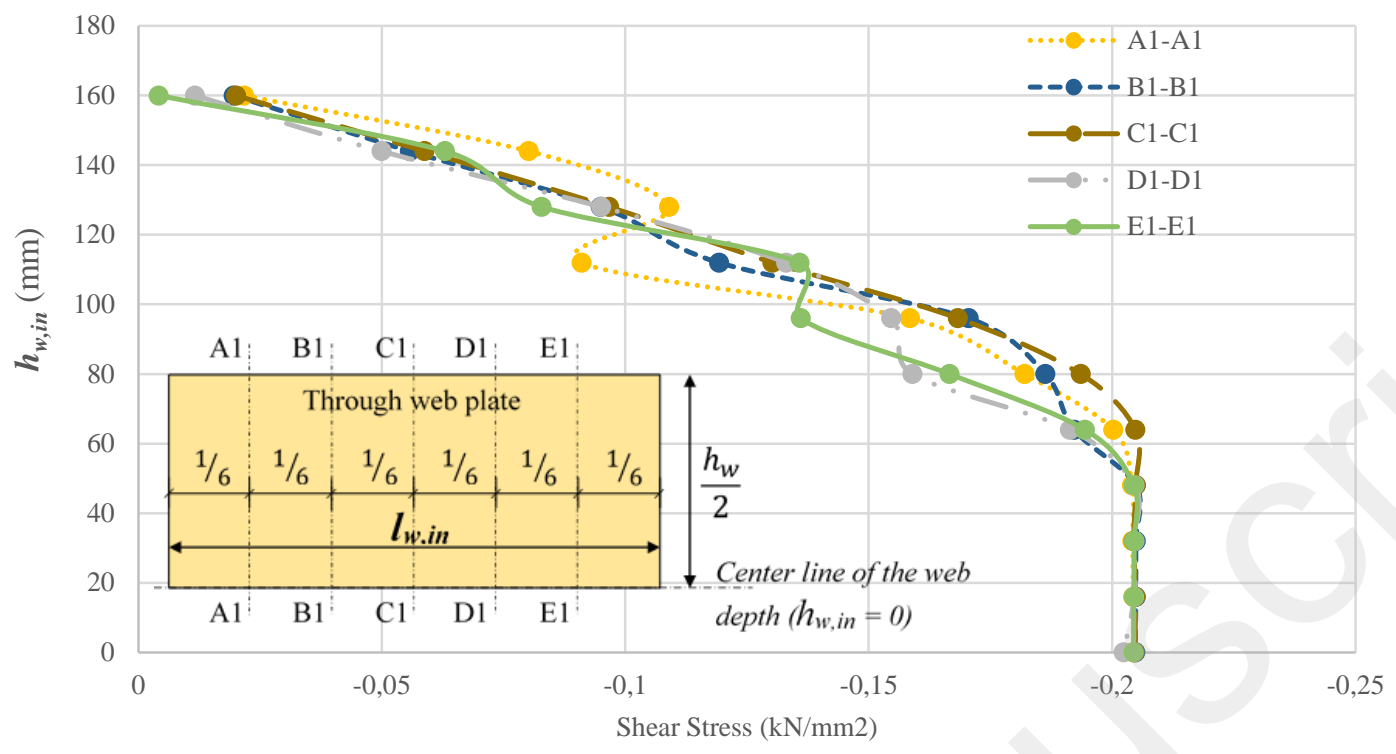

Fig. 34. Shear stress distribution along the depth of the through web plate at failure under LC2

In Fig. 34, $h_{w, i n}$ denotes the depth of the through web plate inside the CHS column starting from its central longitudinal axis $\left(h_{w, i n}=0\right)$ to the topmost fibre $\left(h_{w, i n}=h_{w} / 2=160 \mathrm{~mm}\right)$. Although nineteen vertical cuts were made to understand the stress distribution along the depth of the web plate, only five of them (A1-A1, B1B1....) are plotted in Fig. 34 to avoid overcrowding of data. As shown in Fig. 34, for each and every vertical cut (i.e. a vertical element layer), minimum shear stresses were observed at the outermost fibre of the through web plate $\left(h_{w, i n}=160 \mathrm{~mm}\right)$. However, the shear stresses increased as the elements moved closer to the central longitudinal axis of the through web plate and eventually reached the maximum value $\left(\frac{f_{y}}{\sqrt{3}}=\frac{355}{\sqrt{3}}=\right.$ $\left.0.2 \mathrm{kN} / \mathrm{mm}^{2}\right)$ at $h_{w, i n}=0$. Therefore, an approximate parabolic distribution of shear stresses was obtained along the depth of the through web plate rather than a uniform rectangular distribution.

Similarly, longitudinal cuts were also made on the through web plate (A2-A2, B2-B2...). The shear stress distributions obtained from these cuts are plotted in Fig. 35, along the length of the through web plate. $I_{w, i n}$ denotes the length of the through web plate inside the CHS column (connecting outer faces) where the central vertical axis of the web is denoted by $l_{w, i n}=0$. Minimum shear stress values were again obtained at the longitudinal element "layers" near the outermost fibre of the through web plate (A2-A2). However, the shear stresses increased as the element layers got closer to the centre of the through web plate and eventually reached the maximum value $\left(\frac{f_{y}}{\sqrt{3}}=\frac{355}{\sqrt{3}}=0.2 \mathrm{kN} / \mathrm{mm}^{2}\right)$ at the central longitudinal axis of the through web plate. Furthermore, the shear stress values obtained at each longitudinal cut were averaged w.r.t their distance from the longitudinal axis of the through web plate and has been plotted in Fig. 35 to highlight that, due to such a non-uniform stress distribution, the shear stresses acting through the longitudinal direction of the web plate ( $\tau_{\text {h,avg }}$ in Fig. 8b) was reduced from the actual value of $\tau_{\text {avg }}\left(=0.2 \mathrm{kN} / \mathrm{mm}^{2}\right)$ to $0.15 \mathrm{kN} / \mathrm{mm}^{2}$. 


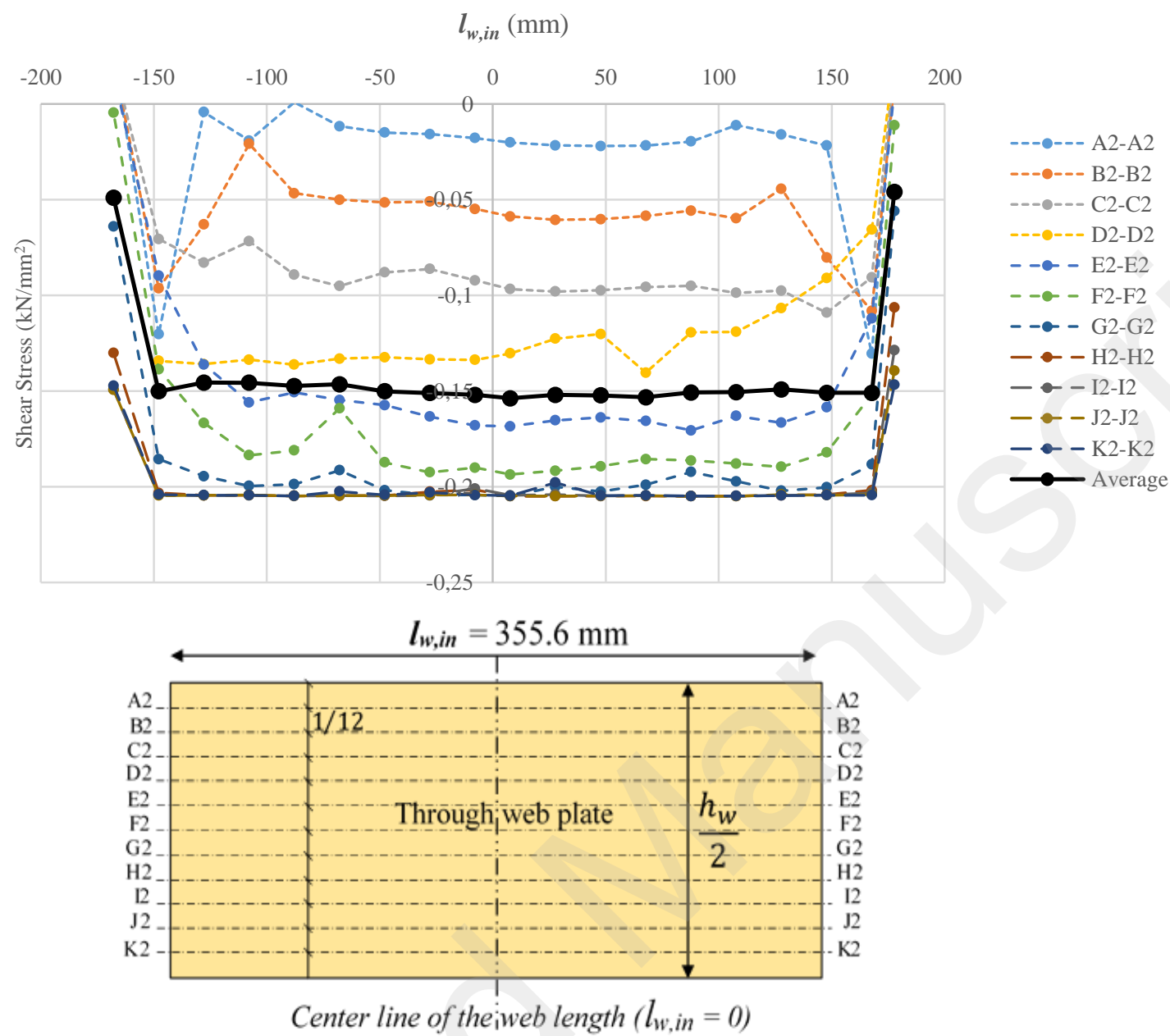

Fig. 35. Shear stress distribution along the length of the through web plate at failure under LC2

According to the basic plastic design principles, an average shear stress, $\tau_{a v g}$, is equal to $\frac{f_{y}}{\sqrt{3}}$, where $f_{y}$ is the material yield strength. However, this $\tau_{\text {avg }}$ can only be used if the section allows a uniform distribution of shear stresses throughout its cross section, which was rather limited for the proposed LASTEICON configuration. As mentioned earlier, although the shear stresses redistributed efficiently along the longitudinal direction of the through web plate, it could not do so in the vertical direction. As a consequence, the $\tau_{h, \text { avg }}$, shear stress along the longitudinal direction of the web plate, was limited to a reduced value of $\frac{f_{y}}{\sqrt{3}}$. So, the basic concepts of maximum shear stress $\left(\tau_{\max }\right)$ was considered to derive the shear strength of the through web plate assuming a parabolic distribution of the shear stresses, where $\tau_{v, \max }=\tau_{v, \text { avg }} / 1.5=\tau_{h, \text { avg. }}$. All the numerical models indicated a similar stress distribution and thus confirmed that although the assumption of $\tau_{\max }$ could prove to be a conservative approach, it certainly offers a significant safety in designing the proposed LASTEICON configuration. Fig. 36 presents the shear stresses distributed in the through web plate for different numerical models studied with actual material characteristics. 
Fig. 36. Shear stress $\left(\mathrm{N} / \mathrm{mm}^{2}\right)$ distribution for (a) $10 \mathrm{~mm}$ thick through web plate with $t_{f}=12 \mathrm{~mm}$, (b) $14 \mathrm{~mm}$ thick through web plate with $t_{f}=12 \mathrm{~mm}$, (c) $18 \mathrm{~mm}$ thick through web plate with $t_{f}=12 \mathrm{~mm}$ at failure under LC2

\subsubsection{Through web plate thickness ( $t_{w}$ ) for High Flange Thickness (HFT)}

Under LC1, the joint panel provided sufficient amount of resistance in all the configurations with a $20 \mathrm{~mm}$ thick through flange plate. As a result, failure occurred due to flexural plasticity in the main beam flanges (as anticipated earlier from Table 1). As the main beams were kept unchanged throughout this parametric variation, all configurations provided identical force-displacement curves without any noticeable difference (Fig. 37). The force-displacement behaviour (Fig. 38) and the failure modes (ultimate joint failure shown in Fig. 39) under LC2 also agreed with the corresponding analytical predictions hence validating the consistency of the proposed design approach. The shear stresses were similarly noticed to be distributed in a parabolic manner along the depth of the through web. Due to qualitative similarity, these distributions are not discussed further.

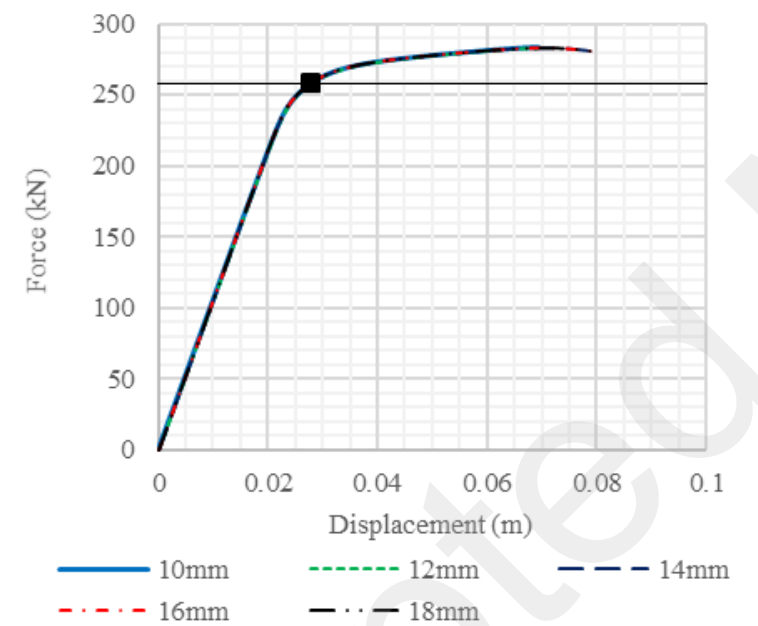

Fig. 37. Vertical force-displacement curve comparisons for varying through web plates for $t_{f}=$ $20 \mathrm{~mm}$ under LC1

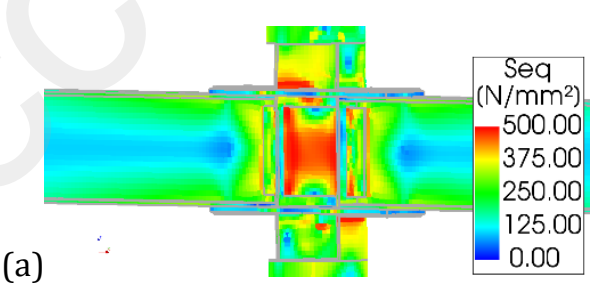

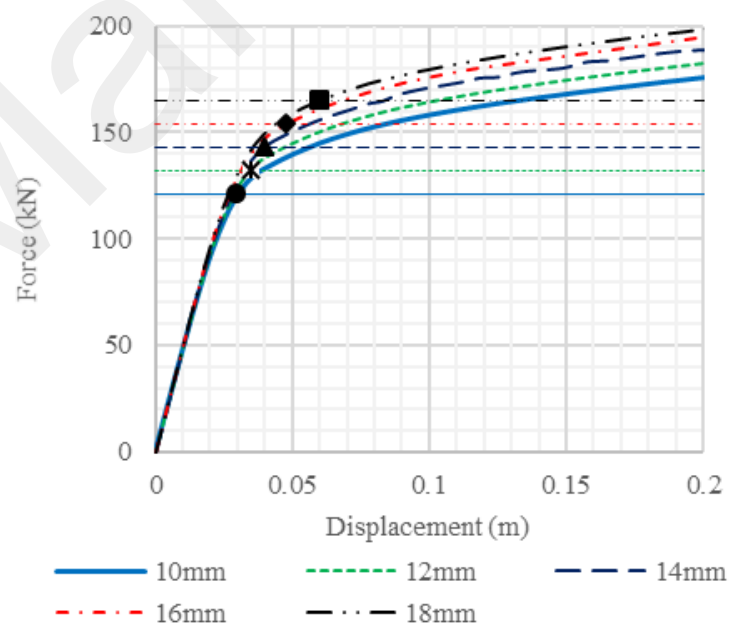

Fig. 38. Vertical force-displacement curve comparisons for varying through web plates for $t_{f}=$ $20 \mathrm{~mm} \quad$ under LC2

(b)

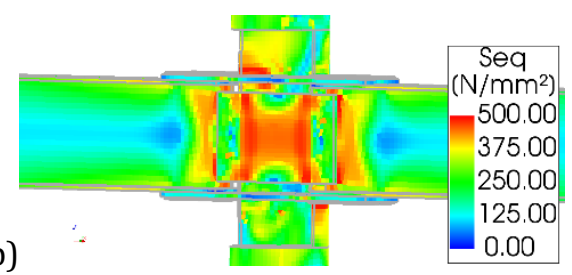

Fig. 39. Von mises equivalent stresses $\left(\mathrm{N} / \mathrm{mm}^{2}\right)$ for models with (a) $10 \mathrm{~mm}$ thick through web plate with $t_{f}=$ $20 \mathrm{~mm}$, (b) $18 \mathrm{~mm}$ thick through web plate with $t_{f}=20 \mathrm{~mm}$, at failure, under LC2 


\subsection{Material properties for both CHS and through plates ( $f_{y c}$ and $f_{y p}$ )}

Different material properties or steel grades were also chosen for the proposed LASTEICON configuration, to identify the failure sequences in the joint panel and also have a consistent verification of the design approach. Primarily, three nominal material properties were chosen for steel grades S275 $\left(f_{y}=275 \mathrm{Mpa}\right)$, S355 $\left(f_{y}=\right.$ $355 \mathrm{Mpa})$, and $\mathrm{S} 450\left(f_{y}=440 \mathrm{Mpa}\right)$ for all members in the joint configuration $\left(f_{y p}=f_{y c}\right)$ as shown in Table 1 and 2. $f_{y}$ stands for the yield strength of a steel grade. In Fig. 40 and 41; "S275N", "S355N" and "S450N" denote the configurations where the aforementioned nominal material properties were adopted according to Table 3.1 (EN 10025-2), EN 1993-1-1. "S355Experiment" denotes the configuration where the real material stress strain curves were used $\left(f_{y p}=420 \mathrm{Mpa}\right.$ for the through plates and main beams and $f_{y c}=377 \mathrm{Mpa}$ for the CHS column). Two more material combinations were also used as shown in Fig. 40 and Fig. 41 where "S355N-S450N (B-T)" defines a model with plates and main beams modelled with S355N and the CHS column modelled with S450N, and "S450N-S355N (B-T)" denotes the opposite combination.

As shown in Fig. 40, the force-displacement curves for "S355N" and "S355N-S450N (B-T)" overlapped more or less perfectly with each other till the through flange plate buckling under LC1. The post buckling behaviour of the latter showed some increased resistance due to the strengthening of the CHS column as discussed in Section 4.1. Almost identical yield strengths were yet again observed for "S450N" and "S450NS355N (B-T)", therefore, validating that under LC1, the failure is solely dominated by the through flange plate buckling without any significant contribution of the CHS column. This can also be noticed from the $V_{b u, s y m}$ values calculated in Table 1. However, no such overlapping was noticed in the force-displacement curves under LC2 as shown in Fig. 41. This justified the design interpretation that both the through web plate as well as the CHS column contributes to the ultimate joint resistance, $V_{b u, o p p}$. Furthermore, as observed in Table 2 and Fig. 41 respectively, the analytical values and the force-displacement curve for "S355N-S450N (B-T)" was closer to "S450N" compared to "S355N" and similarly, "S450N-S355N (B-T)" was closer to "S355N" than "S450N". This observation possibly highlights a slightly larger contribution offered by the CHS column compared to the through web plate under LC2. Von mises equivalent stresses are not further shown as similar qualitative results were obtained for both LC1 and LC2.

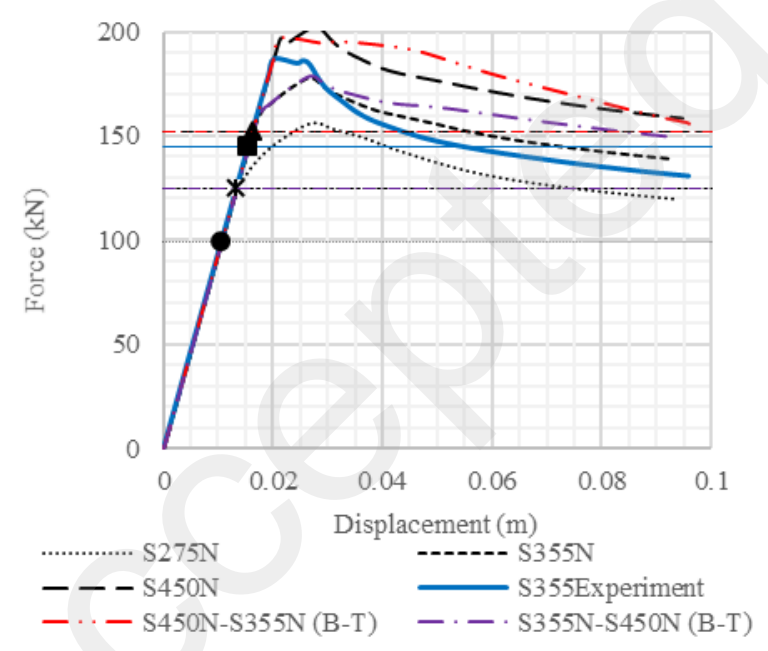

Fig. 40. Vertical force-displacement curve comparisons for varying steel grades with $t_{f}=12 \mathrm{~mm}$ under LC1

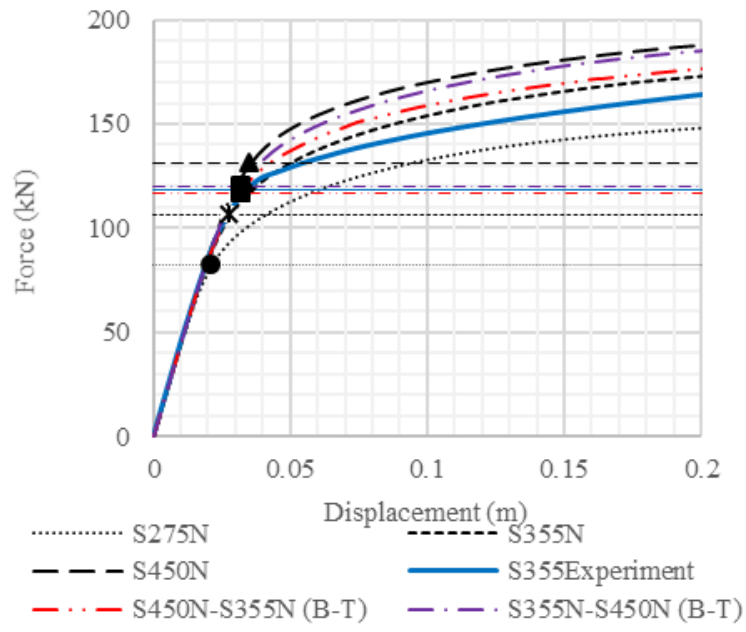

Fig. 41. Vertical force-displacement curve comparisons for varying steel grades with $t_{f}=12 \mathrm{~mm}$ under

\subsection{Moment-to-Shear (M/V) Ratio}

In order to check the consistency of the design approach for different Moment-to-Shear (M/V) ratios, the lever arm distance between the CHS column wall face and the point of load application was varied through the 
overall length of the beam, $L_{b}$. The lengths of the through plates were kept constant as per Fig. 17 throughout all the models. Decreasing the beam length decreased the lever arm and thus produced a smaller moment on the joint panel. As a result, configurations withstood a larger vertical load, whereas, the contrary happened for an increased beam length. The force-displacement curves were compared with relevant analytical calculations in Fig. 42 and 43 respectively for LC1 and LC2 to highlight the consistent agreements found between the analytical calculations listed in Table 1 and 2 and the FE simulations. Von mises equivalent stresses were not further shown due to qualitative similarity.

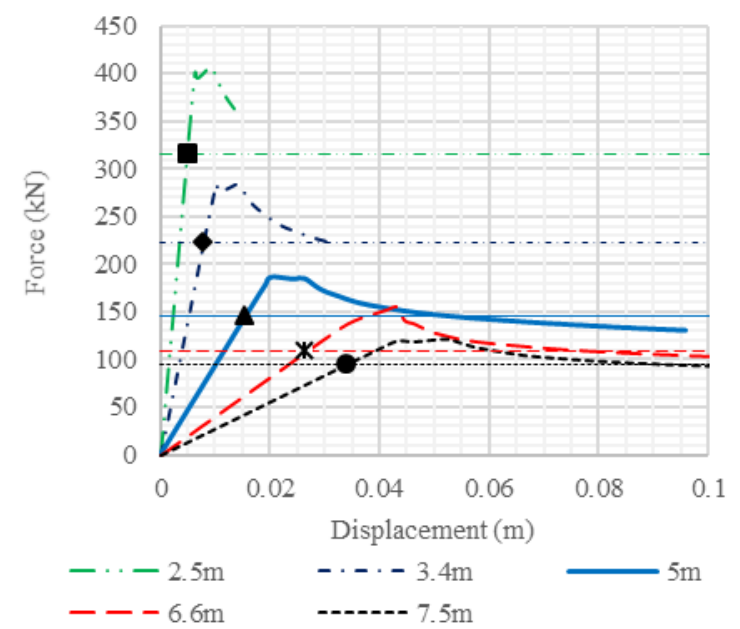

Fig. 42. Vertical force-displacement curve comparisons for varying beam length with $t_{f}$ $=12 \mathrm{~mm}$ under $L C 1$

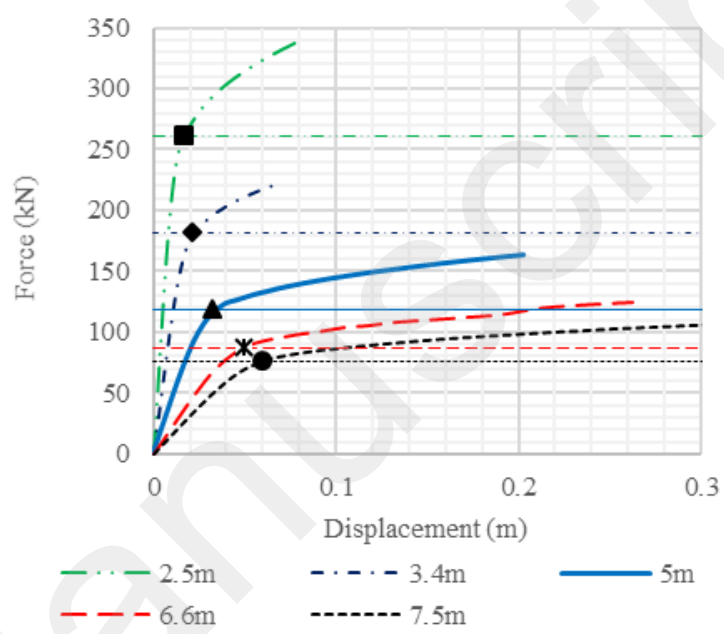

Fig. 43. Vertical force-displacement curve comparisons for varying beam length with $t_{f}$ $=12 \mathrm{~mm} \quad$ under $\quad$ LC2

Although the proposed design approach under LC1 was successfully verified through the abovementioned force-displacement behaviour, all numerical models with such low flange plate thickness $\left(t_{f}=12 \mathrm{~mm}\right)$ failed due to through flange plate buckling in compression as predicted in Table 1. Therefore, as a further verification, an additional parametric variation was also conducted where $L_{b}$ was varied for connections having a high flange plate thickness $\left(t_{f}=20 \mathrm{~mm}\right)$. Good agreements were again obtained between the analytical calculations and numerical results as the successful predictions were obtained in terms of resistance (Fig. 44) as well as failure modes for all configurations.

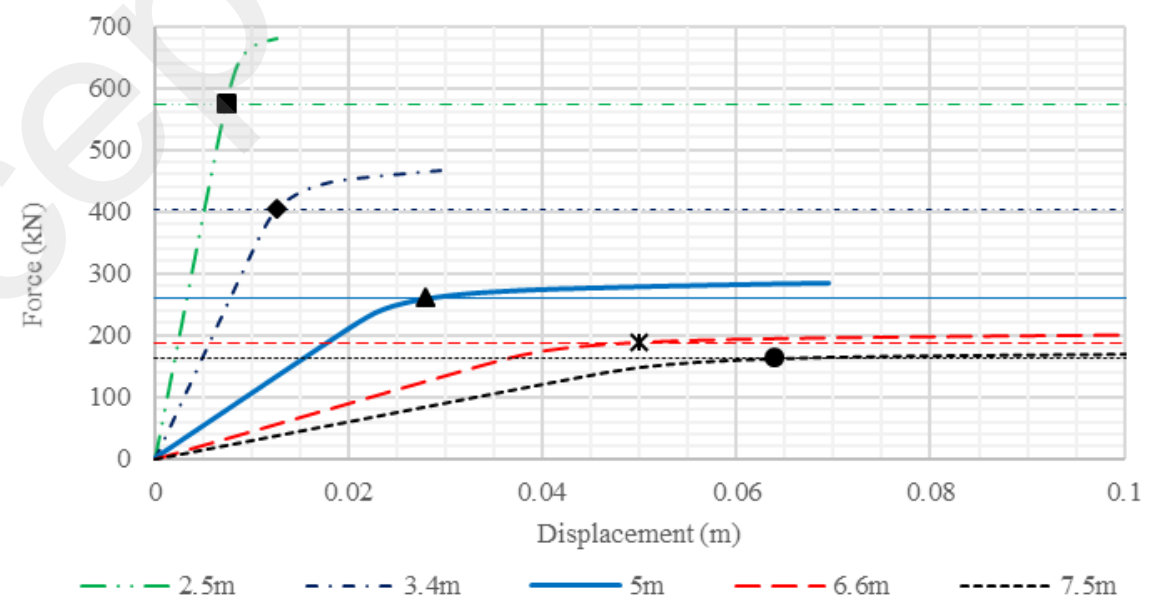

Fig. 44. Vertical force-displacement curve comparisons for varying beam length with $t_{f}=20 \mathrm{~mm}$ under LC1 


\subsection{Comparison with Conventional Plate-to-CHS joint connections}

As discussed in Section 1 and 3, the conventional connection configurations involving flange and web plates directly welded to a CHS column is not completely capable of exploiting the advantages provided by the hollow sections. Therefore, a short comparison study was done in order to see the advantages of the proposed LASTEICON "passing-through" plate-to-CHS connections in terms of strength and stiffness.

As the CHS column governs the failure modes for such conventional connections, only the CHS column thickness was varied to check the minimum thickness required for such connections to match a particular LASTEICON plate-to-CHS configuration. The reference LASTEICON configuration constituted of two IPE400 sections as the main beams connected at each side of the CHS column connection via two $180 \mathrm{~mm}$ wide $20 \mathrm{~mm}$ thick through flange plates and a $320 \mathrm{~mm}$ deep $10 \mathrm{~mm}$ thick through web plate. The CHS column had a diameter $\left(d_{c}\right)$ of $355.6 \mathrm{~mm}$ and a thickness $\left(t_{c}\right)$ of $10 \mathrm{~mm}$ with an overall beam length $\left(L_{b}\right)$ of $5000 \mathrm{~mm}$. Thick flange plates were deliberately used to avoid the brittle failure due to through flange plate buckling inside the CHS column under LC1. The conventional joints were modelled by simply removing the "passing-through" parts of the inserted flange and web plates as well as the slots in the CHS column. The force-displacement curve comparisons are illustrated in Fig. 45 and 46 for LC1 and LC2 respectively. As the through flange plates contribute significantly to the joint resistance of the LASTEICON "passing-through" configuration under LC1, noteworthy advantages were observed in the force-displacement curve comparisons shown in Fig. 45. A conventional connection with $22 \mathrm{~mm}$ thick CHS column proved to be nearly sufficient to provide as much resistance as a LASTEICON configuration with a $10 \mathrm{~mm}$ thick CHS column under LC1. A significant decrease in the stiffness is also observed for the conventional connections due to the removal of the "passing-through" part. Under LC2, a $14 \mathrm{~mm}$ thick CHS column in the conventional connection was observed to be enough resisting as the LASTEICON joint with $10 \mathrm{~mm}$ CHS thickness (Fig. 46). This provides sufficient evidence towards stating that the proposed LASTEICON configuration can serve as an improved alternative to the existing open-to-CHS column connections.

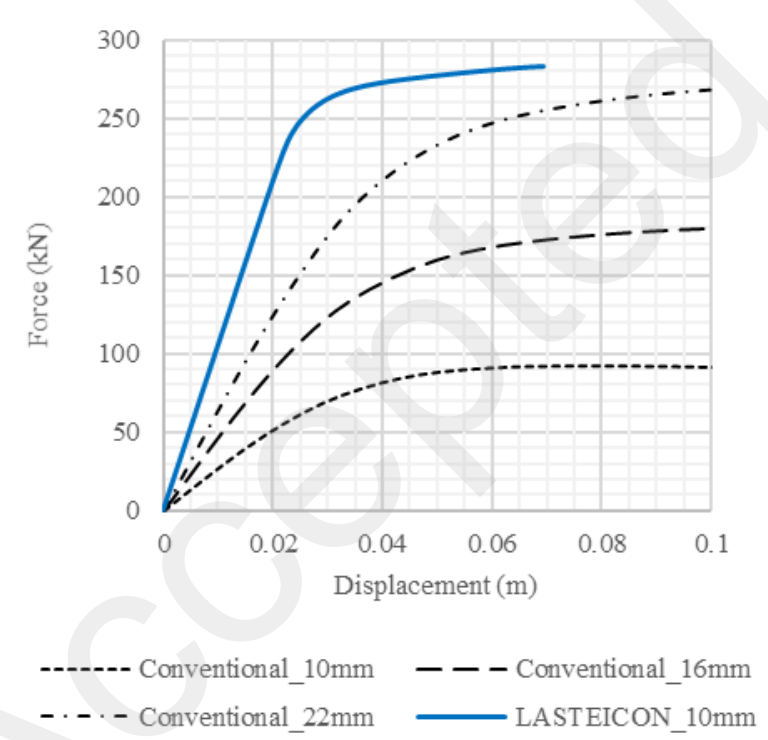

Fig. 45. Vertical force-displacement curve comparisons between LASTEICON and conventional plates-to-CHS connection under LC1

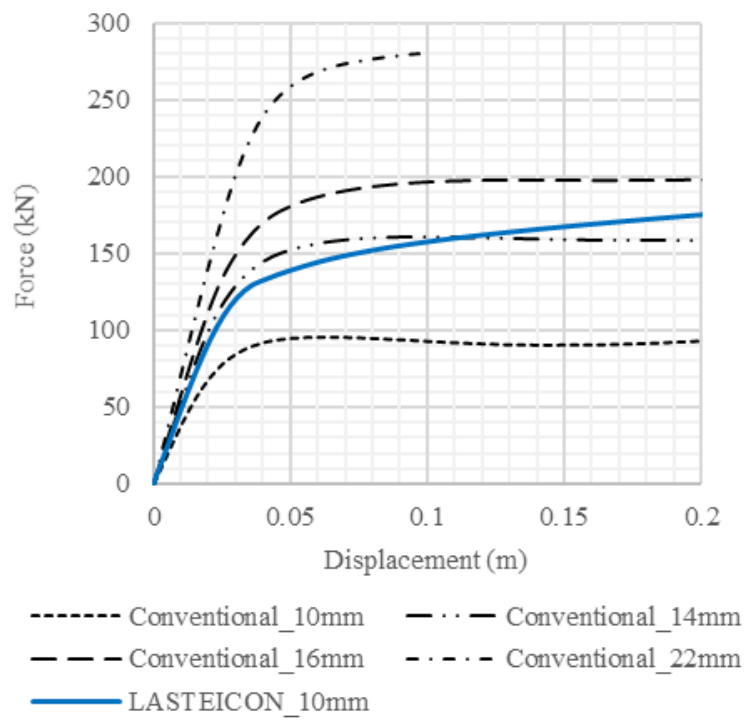

Fig. 46. Vertical force-displacement curve comparisons between LASTEICON and conventional plates-to-CHS connection under LC2 


\section{DISCUSSIONS AND REMARKS}

A parametric study was done based on a series of nonlinear static analyses on several connection models to construct a conservative design method for the LASTEICON "passing-through" Plate-to-CHS connections under two different loading scenarios in accordance with the EN 1993-1 prescriptions. Both design hypothesis was implemented on the proposed configuration to validate the preliminary assumptions regarding the forcetransfer mechanism shared between the through plates and the CHS column and further characterize their contributions towards an efficient connection. This newly proposed LASTEICON connection as well as the design procedures can thus be distinguished as an efficient upgrade to the conventional connections.

- A preliminary experimental campaign was conducted to justify the modelling assumptions. Encouraging agreements obtained in terms of the force-displacement behaviour and the failure modes of the connection configuration provided enough support to the nonlinear numerical simulations.

- A detailed parametric study was conducted by altering six different parameters under both, LC1 and LC2, to validate the corresponding design approaches and the resulting analytical calculations.

- In the monotonic gravitational loading, LC1, two types of failure were noticed: (1) through flange plate buckling under compression followed by through web plate buckling and (2) flexure failure of the main I-beams with eventual plastic flange buckling near the connection zone. A straightforward force-transfer mechanism was identified. Failure type (1) occurs as a localised failure in the joint panel when the through flange plate fails to provide sufficient resistance to the joint panel, and therefore buckles inside the CHS column. After this, the forces are redistributed to the through web plate via the CHS column. When the web plate loses its capacity, it buckles under compressive stresses due to bending. Stresses are again redistributed along the CHS column wall and finally, the ultimate failure occurs due to the compressive crushing of the CHS column wall. On the other hand, if the through flange plates are strong enough to provide necessary resistance against compression Failure type (2) occurs as the main beams fail due to flexural plasticity.

- A fixed-fixed boundary condition was assumed in the design procedure to calculate the critical buckling length of the through flange plate under LC1. Although connections with Class 1, 2 and 3 CHS columns provided good evidence towards the foretold assumption, Class 4 sections were observed to provide a lesser amount of fixity at both ends therefore decreasing the safety margin between the analytical calculations and the numerical results. Therefore, it is strongly recommended to avoid such Class 4 CHS columns in the proposed connections. Furthermore, a thicker CHS column transferred larger amount of forces to the through web plate after the flange plate buckling under LC1. However, the through flange plate buckling was defined as the critical failure mode in the proposed design procedure to prioritize a safe design rather than an optimized prediction technique.

- Decreasing the diameter $\left(d_{c}\right)$ of the CHS decreased the through flange plate length inside the CHS column $\left(l_{f, i n}\right)$, which therefore increased the buckling resistance of the joint under LC1.

- The through flange plate thickness governed the failure mode under LC1. Thicker flange plates were able to resist local buckling due to compressive stresses and therefore triggered the flexural failure of the main beams. The through web plate however influenced the post flange plate buckling behaviour of the joint. Thicker web plates were able to offer a larger resistance even after the through flange plate buckling thus delaying the ultimate failure of the joint panel.

- The load-transfer mechanism as well as the design assumptions under LC2 were similarly investigated and validated through the numerical simulations. For a properly designed configuration (safe from all checks) the joint strength was developed by a combined effort of the through web plate (via transverse shear resistance) and the CHS column wall (via transverse tensile/compressive resistance). 
- Under LC2, the configuration with a $4 \mathrm{~mm}$ thick Class 4 type CHS column indicated its vulnerability against punching shear and thus justified the importance of the corresponding Design Check.

- As the diameter decreased, the through web plate offered a smaller shear resistance but the CHS column wall produced a larger resistance against transverse tension/compression. Due to such an inverse relationship shared between the through web plate and the CHS column resistance, a clear difference could not be illustrated by the force-displacement curves.

- Substantial flexural stresses were noticed to develop at the four corners of the through web plate under LC2. These flexural stresses somewhat prevented a uniform rectangular distribution of shear stresses along the vertical direction of the web plate and consequently reduced the average yield stress in its longitudinal direction. As a consequence, the concept of maximum shear stress $\left(\tau_{\max }\right)$ was assumed where to calculate the shear resistance provided by the through web plate.

- In real life structures, as the CHS column would be axially loaded rather than being an unloaded part of the joint configuration, axial loads would be present and can eventually make the CHS columns vulnerable towards local buckling failure. So, although a local buckling failure was not observed in the present range of investigations under LC2, Design Check 2 is recommended.

- The detailed parametric study based on the numerical simulations validated the analytical approach. Parametric studies with different material combinations and different moment-to-shear ratios specifically highlighted the desired consistency of the proposed design guidelines for both loading scenarios. The importance of the three different Design Checks were also discussed and therefore should not be ignored. However, to avoid such irregular failures, Class 3 and 4 type CHS sections are recommended to avoid while constructing such "passing-through" connections.

- A short comparison study was also conducted between the conventional and the LASTEICON configuration to examine the advantages provided by the proposed "passing-through" connections in terms of strength and stiffness. In a conventional connection under LC1, the CHS column had to be made at least 2.2 times thicker to acquire an equal resistance as a LASTEICON connection with similar geometric/sectional properties. However, under LC2, a 1.4 times thicker CHS column proved to be adequate. Therefore, the newly proposed LASTEICON solution can be comprehended as an improved alternative to the conventional Plate-to-CHS column connections.

However, a certain lack of knowledge remains regarding the deformation properties of such "passingthrough" connections. So, studies are currently being conducted on the relevant joint components to assess their stiffness and deformation capacity. Detailed experimental studies under monotonic and cyclic loading are investigating these aspects. These additional tests are considering different types of welding - fillet welds and full penetration welds - in order to quantify the LCT/welding interaction.

\section{CONCLUSION}

This paper introduces a new type of open-to-hollow section connection through a LASTEIICON solution, which consists of main beams connected to each side of the CHS column via two transverse and one longitudinal plate passing through the CHS column via Laser Cut slots. The force-transfer mechanism is identified through a detailed parametric study of numerical models initially calibrated with experimental prototypes and a design procedure is therefore proposed accordingly to calculate the ultimate resistance offered by these new LASTEICON connections. For a monotonic gravitational loading, the joint strength is determined based on the elastic buckling theory of plates, whereas, under a opposite bending loading scenario, the axial forces in the beam flanges are transferred as horizontal shear forces through the joint and are resisted by the shear strength of the through longitudinal (web) plate as well as the CHS chord resistance against transverse tensile/compressive forces. However, due to non-uniform shear stress distribution in the through web plate, the shear strength is calculated based on $\tau_{\max }$ instead of $\tau_{\text {avg. }}$. Although it might suppose that the proposed design procedure is rather conservative, it provides significant reliability in terms of deriving the ultimate 
resistance of the LASTEICON connections. Good agreements are obtained between the studied design models and the numerical simulations. A brief comparison study between the LASTEICON connection and conventional plate-to-CHS column connection is also presented to highlight the advantages gained from the passing through concept.

However, to further justify and standardize the proposed LASTEICON "passing-through" connection and its design procedure, a detailed experimental campaign with monotonic as well as cyclic loading conditions is planned in the near future. Emphasis will be provided to the ductile capacity of the plate-to-CHS connection, refinement of the proposed design procedure for different welding techniques and influence of the heat effected zone resulting from LCT.

\section{ACKNOWLEDGEMENTS}

This research study was possible thanks to the research fund provided by the European Commission with the contract LASTEICON EU-RFCS GA-709807 (www.LASTEICON.eu). The project consortium includes Fincon Consulting Italia srl (coordinator), RWTH Aachen, University of Pisa, Hasselt University, Instituto Superior Tecnico of Lisbon and INSA Rennes, ADIGESYS, OCAM and VALLOUREC. The cooperation of all of them is hereby gratefully acknowledged.

\section{REFERENCES}

[1] J. Wardenier, J.A. Packer, X.L. Zhao, and G.J. Van der Vegte, Hollow Sections in Structural Applications, CIDECT, Geneva, Switzerland, 2010.

[2] J. Wardenier, Y. Kurobane, J.A. Packer, G.J. van der Vegte and X.-L. Zhao, Design guide for circular hollow section (CHS) joints under predominantly static loading, CIDECT Design Guide 1, 2008.

[3] O.S. Bursi, Prefabricated composite beam-to-column filled tube or partially reinforced-concrete encased column connections for severe seismic and fire loadings, RFSR-CT-2003-00034, Final Report, 2009.

[4] J.F. Demonceau, V.L. Hoang, and J.P. Jaspart, Performance-based Approaches for High Strength Tubular Columns and Connections under Earthquake and Fire Loadings, Final Report, RFSR CT-200800037, 2013.

[5] BLM Group, All in One Tube Technology No: 20. Inspired Tube, 2015.

[6] J. Wardenier, Semi-rigid connections between I-beams and tubular columns, Final Report, ECSC-ECEAEC, Brussels • Luxembourg, 1995.

[7] J. Rondal, K.G. Würker, D. Dutta, J. Wardenier, and N. Yeomans, Structural stability of hollow sections, CIDECT Design Guide 2, 1992.

[8] D. Dutta, J. Wardenier, N. Yeomans, K. Sakae, O. Bucak, and J.A. Packer, Design guide for fabrication, assembly and erection of hollow section structures, CIDECT Design Guide 7, 1998.

[9] Y. Kurobane, J. A. Packer, J. Wardenier, and N. Yeomans, Design Guide for Structural Hollow Section Column Connections, CIDECT Design Guide 9, 2004.

[10] J.A. Packer, D.R. Sherman, and M. Lecce, Hollow Structural Section Connections, Steel Design Guide 24, Steel Design Guide Ser. (2010).

[11] J.P. Jaspart, K. Weynand, Design of hollow section joints using the component method, Proc. 15th Int. Symp. Tubul. Struct (ISTS) (2015) 405-410, Rio Janeiro, Brazil.

[12] J.P. Jaspart, C. Pietrapertosa, K. Weynand, E. Busse, R. Klinkhammer and J.P. Grimault, Development of a full consistent design approach for bolted and welded joints in building frames and trusses between steel members made of hollow and/or open sections - application of the component method volume 1 - practical guidelines, CIDECT Report : 5BP-4/05, August 2005.

[13] Y.M. Alostaz, S.P. Schneider, Connections to concrete-filled steel tubes, A Report on Research Sponsored by the NATIONAL SCIENCE FOUNDATION NSF CMS 93-00682. 
[14] T. Fukumoto, K. Morita, Elastoplastic behavior of panel zone in steel beam-to-concrete filled steel tube column moment connections, ASCE Journal of Structural Engineering 131 (2005), 1841-1853.

[15] I. Nishiyama, T. Fujimoto, T. Fukumoto, K. Yoshioka, Inelastic force-deformation response of joint shear panels in beam-column moment connections to concrete-filled tubes, ASCE Journal of Structural Engineering 130 (2004) 244-252.

[16] S. Morino, K. Tsuda, Design and construction of concrete-filled steel tube column system in Japan, Earthquake Engineering and Engineering Seismology 4 (2002) 51-73.

[17] T. Fujimoto, E. Inai, M. Kai, K. Mori, O. Mori, and I. Nishiyama, Behavior of beam-to-column connection of Cft column system, 12thWorld Conference on Earthquake Engineering (2000) 1-8.

[18] Y.M. Alostaz, S.P. Schneider, Analytical behavior of connections to concrete-filled steel tubes, Journal of Constructional Steel research 40 (1996) 95-127.

[19] N. Kosteski and J.A. Packer, Experimental examination of branch plate-to-RHS member connection types, Proceedings of $9^{\text {th }}$ International Symposium of Tubular Structures, Dusseldorf, Germany, 135144.

[20] N. Kosteski and J.A. Packer, Longitudinal plate and through plate-to-hollow structural section welded connections, ASCE Journal of Structural Engineering 129 (4) 478-486.

[21] N. Kosteski, Branch plate to rectangular hollow section connections, Doctoral Thesis, University of Toronto, Toronto, Ontario, Canada, 2001.

[22] S. Willibald, J.A. Packer, A.P. Voth and X. Zhao, Through plate joints to elliptical and circular hollow sections, Proceedings of the $11^{\text {th }}$ International Symposium on Tubular Structures, Quebec City, Canada, 221-228.

[23] X. Zhao, Branch plate connections to elliptical hollow sections, M.Eng. Thesis, University of Toronto, Toronto, Ontario, Canada.

[24] S.R. Mirghaderi, S. Torabian, and F. Keshavarzi, I-beam to box-column connection by a vertical plate passing through the column, Engineering Structures 32 (2010) 2034-2048. doi:10.1016/j.engstruct.2010.03.002.

[25] A.P. Voth, J.A. Packer, Branch Plate-to-Circular Hollow Structural Section Connections. I: Experimental Investigation and Finite-element Modeling, ASCE Journal of Structural Engineering 138 (8) (2012) 1007-1018. doi: 10.1061/(ASCE)ST.1943-541X.0000545.

[26] A.P. Voth, Branch Plate-to-Circular Hollow Structural Section Connections, Doctoral Thesis, 2010.

[27] V. L. Hoang, J. F. Demonceau, J. P. Jaspart, Resistance of through-plate component in beam-to-column joints with circular hollow columns, Journal of Constructional Steel Research 92 (2014) 79-89. doi:10.1016/j.jcsr.2013.10.001.

[28] A. Kanyilmaz, The problematic nature of steel hollow section joint fabrication, and a remedy using laser cutting technology: A review of research, applications, opportunities, Engineering Structures, 183 (2019) 1027-1048.

[29] R. Moazed, R. Fotouhi, The influence of mechanical and laser cutting on the fatigue strengths of square hollow-section welded T-joints, Journal of Offshore Mechanics and Arctic Engineering, 134 (3) 2012.

[30] A. Kanyilmaz and C.A. Castiglioni, Fabrication of laser cut I-beam-to-CHS-column steel joints with minimized welding, Journal of Constructional Steel Research 146 (2018) 16-32.

[31] C.A. Castiglioni, A. Kanyilmaz, W. Salvatore, F. Morelli, A. Piscini, M. Hjiaj, M. Couchaux, L. Calado, J.M. Proença, B. Hoffmeister, J. Korndörfer, H. Bigelow, H. Degee, R. Das, S. Raso, A. Valli, M. Brugnolli, A. Galazzi, R. Hojda, EU-RFCS Project LASTEICON (Laser Technology for Innovative Joints in Steel Construction), (2016). www.LASTEICON.eu.

[32] European Committee for Standardization, Eurocode 3: Design of Steel Structures - Part 1-5: Plated Structural Elements. EN1993-1-5. October 2006.

[33] European Committee for Standardization, Eurocode 3: Design of Steel Structures - Part 1-1: General Rules and Rules for Buildings. EN1993-1-1. May 2005.

[34] European Committee for Standardization, Eurocode 3: Design of steel structures - Part 1-8: Design of joints. EN1993-1-8. May 2005. 
[35] Final Document of prEN 1993-1-8. European Committee for Standardization, Eurocode 3: Design of steel structures - Part 1-8: Design of joints. July 2018.

[36] J. Wardenier, Hollow Sections in Structural Applications, Delft University of Technology, Netherlands, December 2001.

[37] DIANA User's Manual, DIANA Release 10.2, May, 2018.

[38] DIANA User's Manual, Element Library. User's Manual Release 9.5, February, 2014.

[39] M. Couchaux, V. Vyhlas and M. Hjiaj, RFCS Project LASTEICON Test Report: Tests on Joints C3 and C4, INSA,

Rennes,

March

2019. 